\title{
The effects of quartz recrystallization and reaction on weak phase interconnection, strain localization and evolution of microstructure
}

\author{
Cristiane C. Gonçalves a, b, *, Leonardo Gonçalves ${ }^{\text {a, b, } 1}$, Greg Hirth ${ }^{\text {b }}$ \\ ${ }^{a}$ Departamento de Geologia, Universidade Federal de Ouro Preto, Campus Morro do Cruzeiro, s/n, Ouro Preto CEP: 35400-000, MG, Brazil \\ ${ }^{\mathrm{b}}$ Department of Geological Sciences, Brown University, Providence, RI 02912, USA
}

\section{A R T I C L E I N F O}

\section{Article history:}

Available online 24 December 2014

\section{Keywords:}

Quartz rich aggregates

Load-bearing framework

Matrix-controlled rheology

Weak phase interconnection

Experimental deformation

Shear zone development

\begin{abstract}
A B S T R A C T
We conducted axial compression and general shear experiments, at $T=900{ }^{\circ} \mathrm{C}$ and $P=1.5 \mathrm{GPa}$, on samples of banded iron formation (BIF) and synthetic aggregates of quartz, hematite and magnetite to investigate how dynamic recrystallization of quartz promotes strain localization, and the role of weak second phases (oxides) on the rheology and microstructural evolution of the aggregates. Experiments showed strain localization into oxide rich layers, and that the oxide content and oxide distribution are key factors for the strength of the aggregate. Only 2-10 wt.\% hematite leads to pronounced weakening and increasing hematite content above $\sim 10 \%$ has only a minor additional effect. Where oxide grains are dispersed, the initial strength contrast with quartz induces stress concentrations at their tips, promoting high stress recrystallization-accommodated dislocation creep of quartz. Fine recrystallized quartz reacts with oxide, forming trails of fine reaction product (ferrosilite/fayalite) leading to the interconnection/ percolation of a weaker matrix. The strength contrast between the quartz framework and these finegrained trails promotes strain localization into micro-shear zones, inducing drastic strain weakening. Thus dynamic recrystallization of quartz promotes syn-deformational reactions leading to a microstructurally-controlled evolution of phase strength contrast. It results in a rheologic transition from load-bearing framework to a matrix-controlled rheology, with transition from $\mathrm{S}-\mathrm{C}^{\prime}$ to $\mathrm{S}-\mathrm{C}$ fabric with increasing strain.
\end{abstract}

๑) 2014 Elsevier Ltd. All rights reserved.

\section{Introduction}

The rheology of polyphase aggregates must be analyzed in terms of the relative amounts of constituent mineral phases, grain shapes and their distribution, viscous strength contrast among the phases, the composite structure, metamorphic reactions and deformation mechanisms (e.g. Handy, 1990, 1994; Tullis et al., 1991; Keller et al., 2004; Terry and Heidelbach, 2006). Extrapolating rheological properties of monomineralic to polymineralic aggregates is not applicable if the microfabric and/or bulk rheology change with strain or if one phase is not abundant enough to control the bulk rheology. Tullis et al. (1991), assuming uniform stress and strain

\footnotetext{
* Corresponding author. Departamento de Geologia, Universidade Federal de Ouro Preto, Campus Morro do Cruzeiro, s/n, Ouro Preto CEP: 35400-000, MG, Brazil. Tel.: +55 3135591880 .

E-mail addresses: cristianegeologa@hotmail.com, cristiane@degeo.ufop.br (C.C. Gonçalves), leonardo@degeo.ufop.br, leonardogeologo@hotmail.com (L. Gonçalves), Greg_Hirth@Brown.edu (G. Hirth).

1 Tel.: +553135591600.
}

rate, established that the strength of bimineralic aggregates is mainly affected by volume fractions and that the bulk rheology follows a flow law that includes the equiviscous point for the endmembers. Handy $(1990,1994)$ highlighted the importance of the aggregate microstructure, describing the significance of the loadbearing framework (LBF), where pockets of weak phase are randomly distributed within interconnected grains of strong phase; and the potential for an interconnected weak phase (IWP), when an interconnected matrix or layers of a weak phase surround clasts of a strong phase. The strength of aggregates showing LBF microstructure is controlled by the stronger phase while the IWP structure leads to a matrix-controlled rheology with strength controlled by the weak phase.

The transition from LBF to IWP has been described as a key process for strain weakening observed in experimentally deformed quartz-feldspar aggregates (Dell'Angelo and Tullis, 1996), micaquartz/feldspar (e.g. Shea and Kronenberg, 1992, 1993; Tullis and Wenk, 1994; Rawling et al., 2002; Holyoke and Tullis, 2006a,b,c), muscovite/kaolinite-halite (Neimeijer and Spiers, 2005), halitecalcite aggregates (Jordan, 1987), and even in analogue materials 
such as camphor-octachloropropane (Bons and Cox, 1994). In quartz-feldspar aggregates, quartz is the weaker phase and feldspar grains form the LBF (Dell'Angelo and Tullis, 1996). Experiments on mica-quartz-feldspar aggregates were conducted under conditions for which quartz and feldspar are brittle (e.g. Shea and Kronenberg, 1992, 1993; Rawling et al., 2002) or where stress concentrations at the tips of mica flakes lead to brittle failure of the quartz-feldspar framework or semi-brittle flow of intervening feldspar and quartz (Holyoke and Tullis, 2006a). However, the details of the weakening process and how it leads to strain localization and the maintenance of such zones is not well understood.

Many authors attribute strain localization and weakening to syndeformational reactions, which form fine-grained products enhancing diffusion-accommodated grain boundary sliding (e.g. Rubie, 1990; Rutter and Brodie, 1988, 1995; Newman et al., 1999; Stünitz and Tullis, 2001; Keller et al., 2004; de Ronde et al., 2004, 2005; Holyoke and Tullis, 2006a,b,c; Terry and Heidelbach, 2006). Metamorphic reactions can also influence rheology in several other ways, including: the promotion of high pore pressure owing to dehydration reactions (e.g. Olgaard et al., 1995); crystallization of weak phases that deform easily by crystal plasticity (e.g. Rubie, 1990); weakening owing to transformation plasticity (e.g. Schmidt et al., 2003).

In this study, we investigate how dynamic recrystallization of quartz grains promotes strain localization in polyphase rocks and analyze the role of weak second phases (oxides) on the rheology and microstructural evolution of quartz aggregates. We conducted axial compression and general shear experiments on samples of natural Banded Iron Formation (BIF) and synthetic aggregates composed of quartz, hematite and magnetite to explore (a) the influence of the initial distribution of weak phases (initial mineralogical banding); (b) the effect of viscous strength contrast on stress and strain partitioning and fabric development; (c) the relation between weak phase interconnection and fabric development; and (d) the effect of ductile deformation of quartz framework on strength and weak phase interconnection.

\section{Experimental procedures}

We deformed BIF samples and quartz-iron oxide synthetic aggregates in a Griggs-type apparatus (Tullis and Tullis, 1986). Axial compression experiments were conducted on BIF cores. General shear experiments were conducted on slices of individual quartz-hematite BIF layers and hot-pressed synthetic aggregates. We conducted 24 experiments (Table 1 ) with the following objectives: (a) Five axial compression experiments to analyze the bulk strength of BIF samples and to identify layers with distinct rheological properties. (b) Two hydrostatic experiments to evaluate the extent of reduction reactions with time, which allowed us to investigate the influence of deformation on the reaction rate. (c) Four general shear experiments were conducted on slices of BIF layers with different amounts of oxide to evaluate the role of oxide content and fine-grained reaction products on strain localization. (d) Six general shear experiments were conducted on hot-pressed aggregates of quartz + iron oxide, with initial hematite contents from 2 to 75 wt. $\%$ (one experiment conducted with $25 \%$ magnetite). (e) Three

Table 1

Experimental details.

\begin{tabular}{|c|c|c|c|c|c|c|c|c|c|c|c|c|}
\hline & \multicolumn{2}{|l|}{ Experiment } & \multirow{2}{*}{$\begin{array}{l}T\left({ }^{\circ} \mathrm{C}\right) \\
900\end{array}$} & \multirow{2}{*}{$\frac{P_{\mathrm{c}}(\mathrm{GPa})}{1.5}$} & \multirow{2}{*}{$\frac{\text { Strain rate }}{1.5 \times 10^{-5} / \mathrm{s}}$} & \multicolumn{2}{|c|}{ Sample length (mm) } & \multicolumn{2}{|c|}{$\varepsilon_{\text {flat }}(\%)$} & \multicolumn{2}{|c|}{$t(\mathrm{~h})$ at $P$ and $T^{\mathrm{a}}$} & \multirow{2}{*}{$\begin{array}{l}\text { Iron oxide }(\%)^{b} \\
25-30\end{array}$} \\
\hline \multirow[t]{8}{*}{ Axial compression } & W1530 & BIF samples & & & & 12.08 & & 39 & & 9.37 & & \\
\hline & W1533 & & 900 & 1.5 & & 12.95 & & 42 & & 10.00 & & $10-15$ \\
\hline & W1554 & & 900 & 1.5 & $1.5 \times 10^{-6} / \mathrm{s}$ & 12.93 & & 40 & & 88.93 & & $\sim 20$ \\
\hline & W1556 & & 900 & 1.5 & & 12.36 & & 39 & & 83.07 & & $10-15$ \\
\hline & W1565 & & 900 & 1.5 & $1.5 \times 10^{-5} / \mathrm{s}$ & 12.65 & & 43 & & 64.70 & & $25-30$ \\
\hline & $\mathrm{W} 1549^{\mathrm{H}}$ & & 900 & 1.5 & - & 12.02 & & - & & 10.00 & & - \\
\hline & $\mathrm{W} 1551^{\mathrm{H}}$ & & 900 & 1.5 & - & 12.10 & & - & & 75.00 & & - \\
\hline & & & & & & IST & FST & $\gamma_{1}$ & $\gamma_{2}$ & $T_{\mathrm{c}}$ & $T_{\mathrm{e}}$ & \\
\hline \multirow[t]{14}{*}{ General shear } & W1558 & Synthetic aggregates & 900 & 1.5 & $1.4-1.9 \times 10^{-5} / \mathrm{s}$ & 1.01 & 0.75 & 4.30 & 3.30 & 17.03 & 45.50 & 100 \\
\hline & W1574 & & 900 & 1.5 & & 1.11 & 0.59 & 6.44 & 4.89 & 17.01 & 46.00 & 75 \\
\hline & W1567 & & 900 & 1.5 & & 1.25 & 0.73 & 5.17 & 3.62 & 18.45 & 46.80 & 50 \\
\hline & W1608 & & 900 & 1.5 & & 1.11 & 0.59 & 6.06 & 4.51 & 17.00 & 44.00 & 25 \\
\hline & W1632 & & 900 & 1.5 & & 1.05 & 0.81 & 3.60 & - & 17.00 & 47.00 & 10 \\
\hline & W1650 & & 900 & 1.5 & & 1.02 & 0.69 & 4.29 & - & 17.00 & 44.90 & 2 \\
\hline & W1593 & & 900 & 1.5 & & 1.01 & 0.71 & 4.86 & 3.86 & 17.00 & 47.62 & $100-\mathrm{mgt}^{\mathrm{b}}$ \\
\hline & W1637 & & 900 & 1.5 & & 1.11 & 0.61 & 6.12 & 4.57 & 17.00 & 41.70 & $25-\mathrm{mgt}^{\mathrm{b}}$ \\
\hline & W1592 & & 900 & 1.5 & & 1.01 & 0.85 & 3.86 & - & 17.17 & 43.17 & 0 \\
\hline & W1656 & & 900 & 1.5 & & 1.01 & 0.89 & 1.55 & - & 17.00 & 38.00 & 100 \\
\hline & $\mathrm{W} 1560^{\mathrm{H}}$ & & 900 & 1.5 & - & - & 1.01 & - & & 17.70 & 40.00 & 100 \\
\hline & $\mathrm{W} 1582^{\mathrm{H}}$ & & 900 & 1.5 & - & - & 1.25 & - & & 18.62 & 40.00 & 50 \\
\hline & $\mathrm{W} 1583^{\mathrm{H}}$ & & 900 & 1.5 & - & - & 1.01 & - & & 17.30 & 21.00 & 0 \\
\hline & & & & & & & & $\gamma$ & & & & \\
\hline \multirow[t]{4}{*}{ General shear } & W1676 & BIF layers & 900 & 1.5 & $1.4-1.9 \times 10^{-5} / \mathrm{s}$ & 1.10 & 1.10 & 1.23 & & 24.47 & & $\sim 3$ \\
\hline & W1587 & & 900 & 1.5 & & 1.38 & 1.02 & 3.50 & & 46.00 & & $5-7$ \\
\hline & W1600 & & 900 & 1.5 & & 1.00 & 0.79 & 4.45 & & 46.43 & & $5-7$ \\
\hline & W1625 & & 900 & 1.5 & & 1.00 & 0.62 & 6.00 & & 45.08 & & $\sim 25$ \\
\hline
\end{tabular}

$T_{\mathrm{c}}$ time for compaction; $T_{\mathrm{e}}$ time running the experiment.

$\gamma$ : shear strain.

$\gamma_{1}$ calculated shear strain (according to Heilbronner and Tullis, 2006).

$\gamma_{2}$ corrected shear strain $\left(\gamma_{1}-\right.$ shear strain at the yield).

IST: initial sample thickness.

FST: final sample thickness.

a Experiment run time. Samples were kept under experimental conditions between 15 and 19 h prior deformation.

b Initial hematite content, except for the samples W1593 and W1637, for which magnetite (mgt) powder was used. 
general shear experiments were conducted on hot-pressed aggregates of pure quartz, hematite and magnetite (one experiment of each) to evaluate the viscous strength contrast among these phases. (f) Three hydrostatic tests and one low strain experiment were performed to characterize strength, porosity (extent of compaction) at the yield point and the initial sample thicknesses of the synthetic aggregates.

\subsection{Starting material}

\subsubsection{Natural samples}

We use BIF samples from the district of Itabira, in the northeastern region of Quadrilátero Ferrífero (MG - Brazil) (e.g. Rosière et al., 2001, 2008), exhibiting layers with different proportions and distributions of quartz and hematite. Individual layers show thicknesses from few millimeters to centimeters and tabular to lens shape. Specular hematite occurs as flakes aligned parallel to compositional layering, defining a foliation. Two different types of samples are defined by the degree of banding: (i) samples with strong banding (SB, Fig. 1a), showing well developed quartz bands (up to few centimeters thick) and (ii) samples with weak banding (WB, Fig. $1 \mathrm{~b}-\mathrm{c}$ ), in which compositional banding is more diffuse owing to dispersed specular hematite grains that define a strong foliation.

The WB samples, which contain 25-30 vol.\% hematite, exhibit thin through-going hematite layers and quartz-richer layers in which up to $15-20 \%$ hematite defines an interconnected network of hematite platelets. In contrast, SB samples, which contain
10-15 vol.\% hematite, are characterized by interlayering of hematite-rich bands (comprised of $50-90 \%$ of hematite) and nominally pure quartz bands (with up to $95 \%$ of quartz). Grain size was measured on optical micrographs using the line-intercept method. The measurements were carried out in lines parallel and perpendicular to the foliation and for sheared samples the lines were parallel and perpendicular to the shear plane. The average grain sizes and mean aspect ratio from frequency histograms are presented.

The quartz grain size is much larger in the quartz-rich layers of the SB samples (average grain size is between 170 and $200 \mu \mathrm{m}$ ) than in the hematite-rich layers of the SB samples or in the WB samples (no grains larger than $50 \mu \mathrm{m}$ ) (Fig. 1d-e). In general, quartz grains are free of intracrystalline deformation in both SB and WB samples (Fig. 1d), although slight undulatory extinction can be observed. Quartz-quartz interfaces are commonly straight and grains tend to meet at dihedral angles of ca. $120^{\circ}$ in nominally pure quartz layers (Fig. 1d).

Natural samples experimentally deformed in general shear were cored at $45^{\circ}$ to the foliation, making the shear plane parallel to the compositional layering/foliation. Three of these samples had a load bearing framework fabric of quartz with dispersed grains of iron oxides (initially hematite); these samples contained approximately 3,5 and $6 \%$ of specular hematite (W1676, W1587, W1600, respectively). One sample contained interconnected layers of hematite ( $25 \%$ of hematite - W1625). All samples deformed in axial compression were cored perpendicular to the compositional layering/foliation.
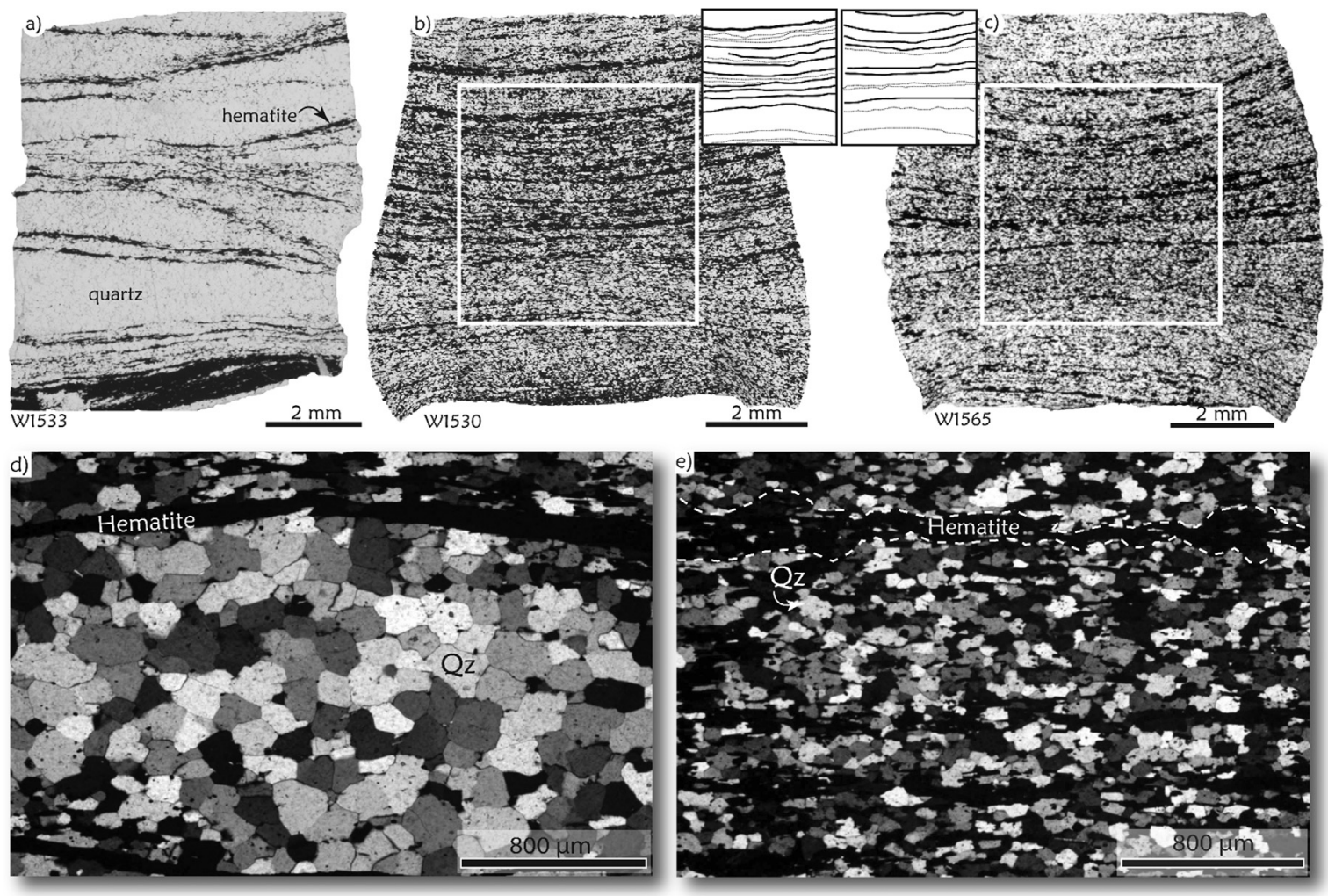

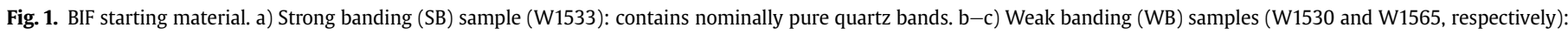

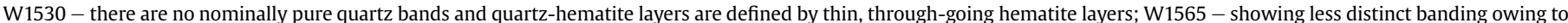

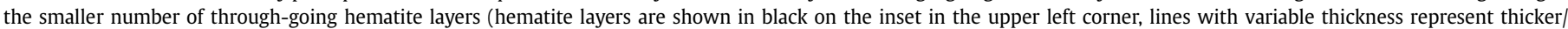

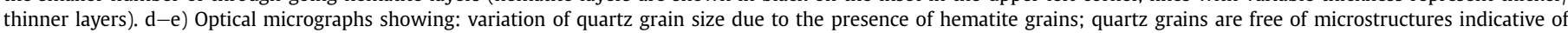

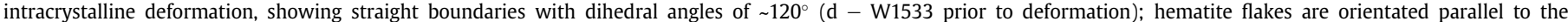

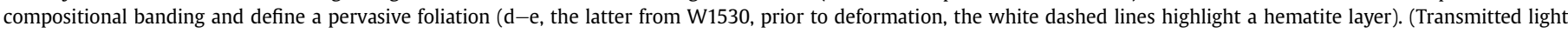
$(\mathrm{a}-\mathrm{c})$; crossed polarized light $(\mathrm{d}-\mathrm{e}) . \mathrm{Qz}=$ quartz. Dark layers are composed of hematite grains). 


\subsubsection{Hot pressed aggregates}

Fine-grained aggregates were produced by hot-pressing hematite, quartz and synthetic magnetite powders at $300{ }^{\circ} \mathrm{C}$ and a confining pressure of $1.3 \mathrm{GPa}$, for about $17 \mathrm{~h}$ prior to the deformation experiment. Hot-pressing was conducted at low temperature to limit the reaction of hematite to magnetite prior to deformation. Powders were produced by crushing fragments of Black Hills quartzite, which has been used in numerous previous studies and hematite ore, both sieved to a grain size fraction between 37 and $53 \mu \mathrm{m}$. The mean grain size of the magnetite powder is approximately $18 \mu \mathrm{m}$ (the same material was used by Yu et al., 2002). Black Hills quartzite contains $<1$ vol.\% of feldspar, iron oxides and clays, and trace amounts of apatite, zircon and rutile (Holyoke and Tullis, 2006a; Chernak et al., 2009). Hematite powders was made from natural samples from Quadrilátero Ferrífero (MG - Brazil) and contains <2 vol.\% quartz.

The amount of quartz and/or iron oxide powders used in each experiment was chosen to produce hot-pressed aggregates with a vertical thickness of $1.4 \mathrm{~mm}$ (assuming no porosity). We prepared samples with initial hematite contents of $2,10,25,50$ and $75 \mathrm{wt}$. \%. The pure magnetite aggregate and the quartz +25 wt.\% magnetite aggregate were also prepared in this manner. All two-phase aggregates were produced by mechanically mixing powders prior to hot-pressing.

Samples were stored in an oven at $140{ }^{\circ} \mathrm{C}$ for at least $12 \mathrm{~h}$ prior to assembly to limit absorption of atmospheric water. Samples are referred to "as-is" because they were not vacuum-dried and water was not added. The water content of Black Hills quartzite is variable, and estimated to be between 0.06 wt. \%, measured by Karl-Fischer titration (Stipp et al., 2006) and 0.1-0.15 wt.\%, measured by weight loss after vacuum drying at $800{ }^{\circ} \mathrm{C}$ for $10 \mathrm{~h}$ (Hirth and Tullis, 1991). The Karl-Fischer titration method is more accurate, but owing to sample-to-sample variability, the possible range in water content should be taken into account.

\subsection{Sample assembly}

For axial compression experiments, cores were cut and polished to produce flat and parallel end surfaces on cylindrical samples $12.7 \mathrm{~mm}$ long and $6 \mathrm{~mm}$ in diameter (Fig. 2a). For general shear

\section{All- $\mathrm{NaCl}$ sample assembly}

a) Axial Compression

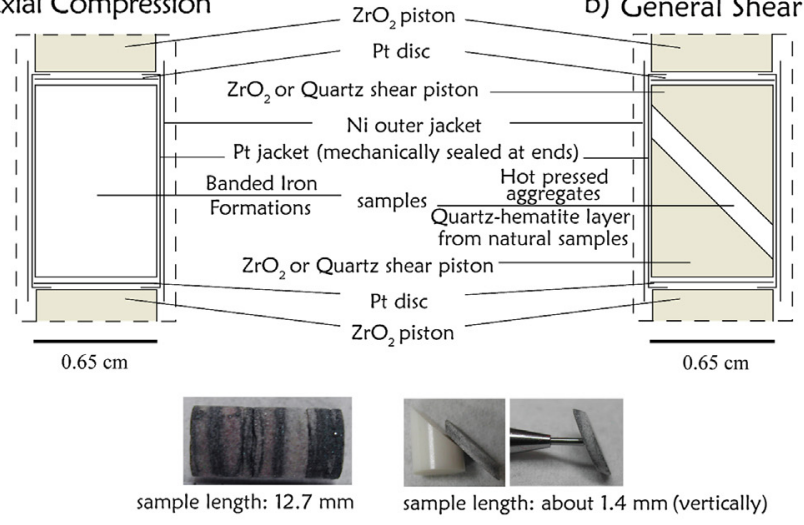

Cylindrical samples with a diameter of $6.4 \mathrm{~mm}$ and length of $12.7 \mathrm{~mm}$. experiments, slices of BIF layers (vertical thickness $1.4 \mathrm{~mm}$ ) or quartz and/or iron oxide powders were placed between two forcing blocks (shear pistons) pre-cut at $45^{\circ}$ (Fig. 2b). $\mathrm{ZrO}_{2}$ (Yttria-stabilized zirconia) and dry synthetic quartz crystals were used as forcing blocks; the quartz crystals were cored parallel to the $c$-axis to provide maximum strength (Muto et al., 2011). The lower shear piston was slid into the Pt jacket, whose bottom edge was sealed; the sample was then positioned on the bottom shear piston, using a metal rod to evenly pack powders before sliding the top shear piston into the jacket; finally, the top jacket edge was sealed. The dimensions of the shear forcing blocks plus sample corresponded to the dimension of the cores used for axial compression experiments (Fig. 2a-b). All samples were mechanically sealed by folding the end of a Pt jacket over Pt discs placed on the end of each sample (or forcing blocks), and then slid inside an outer Ni jacket (wall thickness for both jackets was $0.127 \mathrm{~mm}$ ) that overlapped the $\mathrm{ZrO}_{2}$ pistons used as deformation pistons (Fig. 2a-c).

Temperature was controlled by the electrical power to the graphite furnace and measured using a Pt-Pt10\%Rh thermocouple, placed next to the Ni jacket (Fig. 2c). The lengths of deformation pistons were determined to place the thermocouple at the sample center (Fig. 2c). $\mathrm{NaCl}$ was used as the confining medium. The careful design of the sample assembly guarantee temperature at the sample ends within a few percent of the maximum temperature (approximately $30^{\circ} \mathrm{C}$ for a sample temperature of $900{ }^{\circ} \mathrm{C}$ ), for the adopted geometry. The axial load is measured with an external load cell, and the displacement is measured with a direct current differential transformer.

\subsection{Experimental conditions and methods}

The experimental conditions were chosen so that dislocation creep was the dominant deformation mechanism for quartz and hematite (Hirth and Tullis, 1992; Siemes et al., 2003, 2008). Samples were deformed at $900{ }^{\circ} \mathrm{C}$ and a confining pressure of $1.5 \pm 0.1 \mathrm{GPa}$, at axial strain rates of $1.5 \times 10^{-5} / \mathrm{s}$ and $1.5 \times 10^{-6} / \mathrm{s}$ for axial compression experiments and shear strain rates between $1.4-1.9 \times 10^{-5} / \mathrm{s}$ for general shear experiments (in which the axial strain rate is set by the $1.83 \times 10^{-5} \mathrm{~mm} / \mathrm{s}$ displacement rate). The procedure adopted to bring samples to the experimental condition

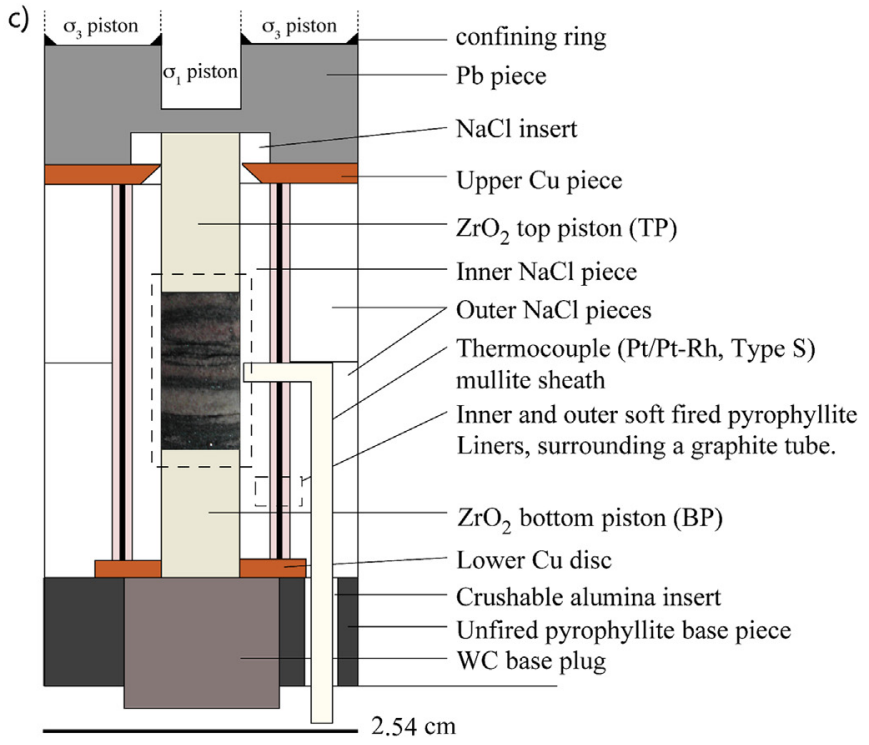

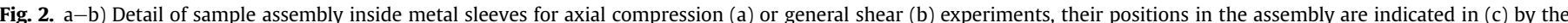

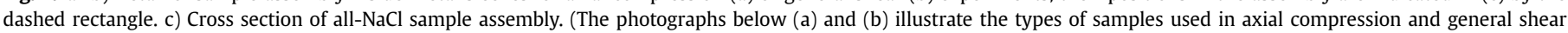
respectively: a cylindrical sample and a sample slice on the shear piston). 
was based on techniques presented by Kronenberg and Tullis (1984) and Post and Tullis (1998). Temperature and pressure were raised stepwise: to $100^{\circ} \mathrm{C}$ at $250 \mathrm{MPa}$, to $200^{\circ} \mathrm{C}$ at $400 \mathrm{MPa}$, to $300{ }^{\circ} \mathrm{C}$ at $600 \mathrm{MPa}$; then pressure was raised to $1.3 \mathrm{GPa}$. From this point, we increased the temperature up to $900{ }^{\circ} \mathrm{C}$ in increments of $100{ }^{\circ} \mathrm{C}$, resulting in a pressure increase from 1.3 to $1.5 \mathrm{GPa}$.

Axial compression experiments on BIF cores were performed to axial strains of $\sim 40 \%$ at $10^{-5} / \mathrm{s}$ and $10^{-6} / \mathrm{s}$. In addition, a strain rate stepping experiment was conducted with an initial strain rate of $10^{-5} / \mathrm{s}$ to $15 \%$ strain, $10^{-6} / \mathrm{s}$ to a total strain of $30 \%$, and then back to $10^{-5} / \mathrm{s}$ to a total strain of $42 \%$. General shear experiments were performed to shear strains $(\gamma)$ of 1.6-4.8 (Table 1 ).

At the end of all experiments, samples were quenched under load to $300{ }^{\circ} \mathrm{C}$, at a rate of $\sim 2{ }^{\circ} \mathrm{C} / \mathrm{s}$, to preserve microstructures. Confining pressure and load were decreased slowly to minimize unloading cracks. Samples were cut longitudinally; one half was then impregnated with epoxy and used to prepare doubly polished thin sections.

\subsection{Strength determination}

Differential stress and axial strain were calculated from the load and displacement data recorded during experiments. Force and displacement were corrected for apparatus distortion, pressure variation and the change in sample diameter, assuming samples deformed homogeneously with no volume change. For general shear experiments, shear stress and shear strain $(\gamma)$ were calculated following the method described by Heilbronner and Tullis (2006) that accounts for progressive shear accompanied by progressive thinning of the sample and progressive change of overlapping area of shear pistons. Shear strain was also calculated based on offsets of shear pistons, discounting offsets related to sliding along the piston interfaces. Shear strains calculated by the piston offsets are within $\sim 0.5$ of that calculated from the axial displacement. Sample thicknesses vary as a function of compaction and hematite alignment during general shear experiments, which we accounted for in the analysis of shear strain (corrected shear strain, $\gamma_{2}$, in Table 1). Values of shear strain were corrected for samples with initial amount of hematite higher than $10 \mathrm{wt}$ \% $\left(\gamma_{2}\right)$. The shear strain at the yield was subtracted from the final calculated value, ending up with maximum $\gamma$ of 4.9 , instead of $6.4\left(\gamma_{2}\right.$, sample starting with 75 wt. \% of hematite). Data are discussed and interpreted in terms of corrected values of $\gamma$.

Based on the results of Gleason and Tullis $(1993,1995)$ at $900{ }^{\circ} \mathrm{C}$ and confining pressure of $1.5 \mathrm{GPa}$, the strength of all- $\mathrm{NaCl}$ confining medium assembly is negligible compared to the resolution of sample strength. Based on these earlier studies, we did not apply a friction correction (c.f., Holyoke and Kronenberg, 2010). Moreover, comparisons between our results and previous studies on iron oxide aggregates conducted in the gas apparatus (Siemes et al., 2003) indicate that effects of piston friction are limited, although those authors used lower confining pressures. Siemes et al. (2003) deformed hematite aggregates at $900{ }^{\circ} \mathrm{C}$ and a confining pressure of $400 \mathrm{MPa}$ and observed a strength of $\sim 270 \mathrm{MPa}$ at $10^{-5} / \mathrm{s}$, and $\sim 110 \mathrm{MPa}$ at $10^{-6} / \mathrm{s}$; these differential stresses are similar or even higher than we observe at $10^{-5} / \mathrm{s}$ and very similar to what we observe at $10^{-6} / \mathrm{s}$, respectively (see results).

\section{Results}

\subsection{Mechanical data}

\subsubsection{Natural aggregates}

For axial compression experiments (Fig. 3a-b), differential stress versus axial strain curves for BIF samples show the effect of initial oxide content, initial compositional banding and strain rate on sample strength. The sample with the highest quartz content ( 90\%) and strong banding (SB, W1533), has the highest peak stress, $325 \mathrm{MPa}$ ( $\varepsilon=15 \%$ ), which is followed by strain weakening to steady state flow stress of $\sim 270 \mathrm{MPa}(\varepsilon=35 \%$, Fig. 3a). The stress versus strain curve is similar to that of Black Hills Quartzite deformed at similar conditions (Fig. 3a), although $200 \mathrm{MPa}$ weaker. One WB sample with $\sim 15 \%$ iron oxide content is considerably weaker, showing a flow stress of around $90 \mathrm{MPa}$ at $10^{-5} \mathrm{~s}^{-1}$ (Fig. 3a - W1530). At similar oxide contents, the strengths of samples with more dispersed oxide phase (i.e., weaker banding) are
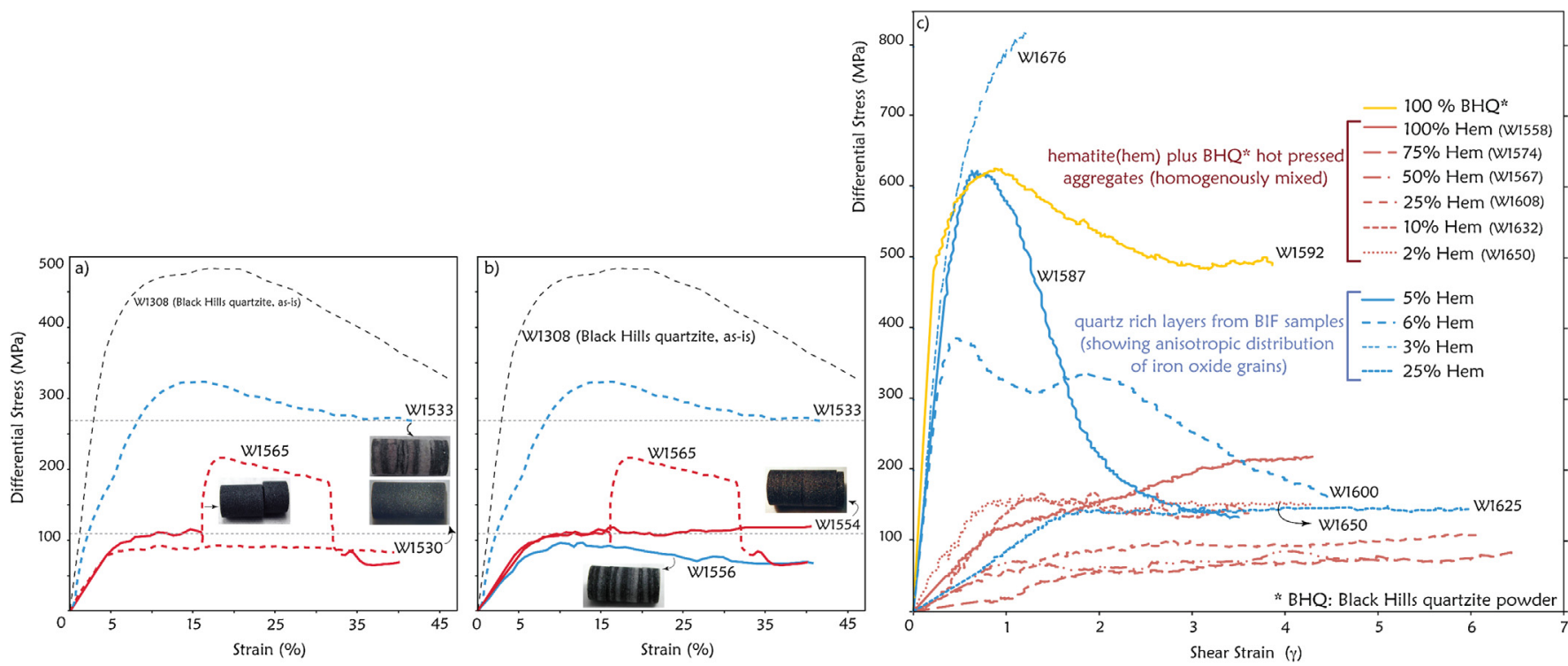

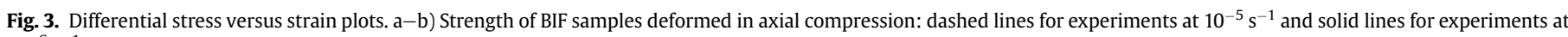

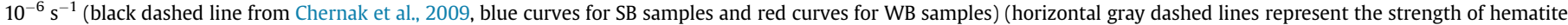

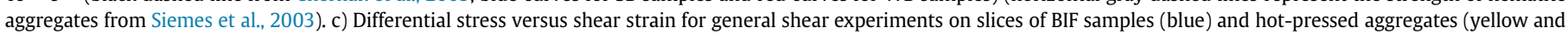
red). (For interpretation of the references to color in this figure legend, the reader is referred to the web version of this article.) 

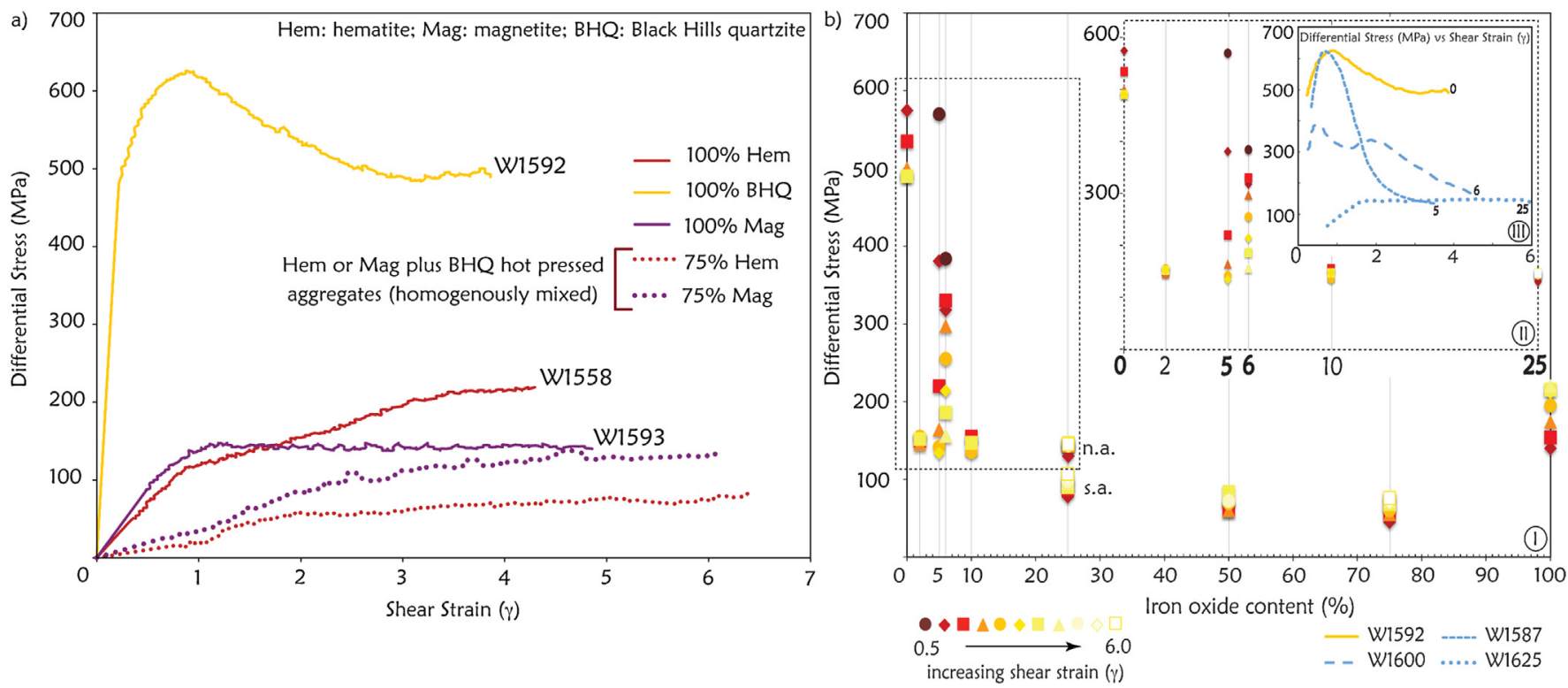

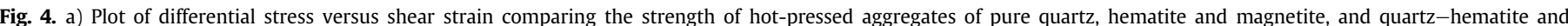

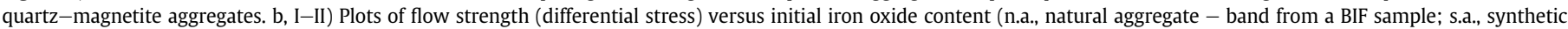

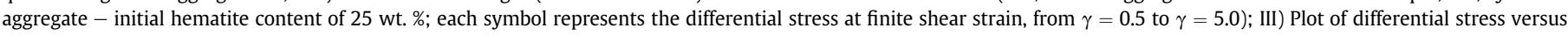
shear strain comparing the strength of the hot-pressed quartz aggregate and three bands from BIF samples (the dotted line represents the sample W1625, from Fig. 5c).

variable. The sample with weaker banding is 100 MPa weaker than that of the sample with stronger banding (compare samples W1565 and W1530 in Fig. 3a, see also Fig. 1b-c). The SB sample with 15 vol.\% oxide (W1556 in Fig. 3b) is the weakest. The effect of strain rate on strength is illustrated by the strain rate stepping experiment, which shows a flow stress of $\sim 110 \mathrm{MPa}$, at $10^{-6} \mathrm{~s}^{-1}$, a stress of $215 \mathrm{MPa}$ at $10^{-5} \mathrm{~s}^{-1}(\varepsilon=\sim 15 \%)$, and a stress of $\sim 65 \mathrm{MPa}$ when the strain rate is decreased back to $10^{-6} \mathrm{~s}^{-1}(\varepsilon=35 \%)$. These data show general agreement with the strengths of the SB (W1556) and WB (W1554) samples deformed at similar conditions.

The influence of oxide content is also apparent in the general shear experiments on the natural BIF samples (Fig. 3c). The sample with the highest quartz content $(\sim 97 \%)$ has the highest peak stress, $\sim 820 \mathrm{MPa}(\gamma=1.2)$ (Fig. 3c, W1676). A modest increase in hematite content promotes a significant weakening effect. The sample with five percent hematite has a peak stress of $\sim 615 \mathrm{MPa}(\gamma=0.7)$, which is followed by dramatic strain weakening to a steady state flow stress at $\sim 135 \mathrm{MPa}$ (Fig. 3c, W1587). The sample with a higher hematite content ( $25 \%$, W1625, Fig. 3c) ends up at a steady state flow stress ( $145 \mathrm{MPa}$ ) similar to the samples with lower hematite content, but does not show the high initial peak stress. All of these samples showed progressive thinning with progressive shear, with maximum values between 20 and $30 \%$.

\subsubsection{Synthetic aggregates}

The general shear experiments on synthetic hot-pressed aggregates of quartz, hematite and magnetite further demonstrate the influence of oxide content and strain on the strength of the quartz + oxide samples (Fig. 3c). In Fig. 4, these data are compared to the strength of synthetic samples comprised of $100 \%$ quartz, hematite and magnetite. The 100\% quartz aggregate has a peak stress of $\sim 625 \mathrm{MPa}$ ( $\gamma=0.9$ ), and strain weakens to a steady state flow stress of $\sim 490 \mathrm{MPa}$ (after $\gamma=2.8$ ) (Figs. 3c and $4 \mathrm{a}-$ yellow curve - W1592). The $100 \%$ hematite and magnetite aggregates are significantly weaker. The hematite aggregate, even after strain hardening, shows a differential stress of $\sim 220 \mathrm{MPa}$ at high strain $(\gamma=3.3)$, while the magnetite aggregate shows a steady stress of $\sim 140 \mathrm{MPa}(\gamma=3.8)$ (Fig. 4a). Both mixtures of hematite $75 \%-$ quartz $25 \%$ and magnetite $75 \%$ - quartz $25 \%$ are weaker than the pure magnetite and hematite aggregates. Even a small amount of hematite ( $2-10 \%$ by weight) promotes pronounced weakening (Figs. 3c and 4b, I-III). All of the initially two-phase aggregates are weaker at high strain than the end-member quartz and hematite aggregates.

\subsection{Reaction}

All samples showed at least some reduction of hematite to produce magnetite, and based on the two hydrostatic experiments (10 and $75 \mathrm{~h}$, under experimental conditions) the extent of reaction is clearly time dependent (Fig. 5a-b). Additionally, the observation of magnetite grains randomly distributed throughout many of the deformed samples (Fig. 5c-d), while being restricted to the rims of hydrostatic samples, suggests that the reduction reaction is enhanced by deformation. These observations indicate that a reducing environment is imposed by the assembly. Previous studies indicate that the oxygen fugacity of the assembly lies near the $\mathrm{Ni}-\mathrm{NiO}$ buffer (Chernak et al., 2009), indicating that the oxygen fugacity is buffered by the oxidation of the outer Ni jacket.

Reaction between quartz and iron oxides (hematite and magnetite) was observed in samples deformed by axial compression and general shear. Minor amounts of fayalite and ferrosilite were identified restricted to the bottom of one sample (where strain is greater, as indicated by the sample shape) deformed in axial compression, and as thin trails parallel to compositional banding/foliation (Fig. 6a-c). Fine-grained fayalite and/or ferrosilite are also observed in sheared samples, forming trails connecting clusters of iron oxide and surrounding iron oxide grains (Fig. 6d-e). The interface between quartz and iron oxides is made up of finegrained reaction products (Fig. 6f). Again, the occurrence of reaction around and within those samples deformed by general shear experiments suggests that the reaction was enhanced by deformation, owing to the fact that the compared experiments were conducted for the same amount of time as the hydrostatic tests. 


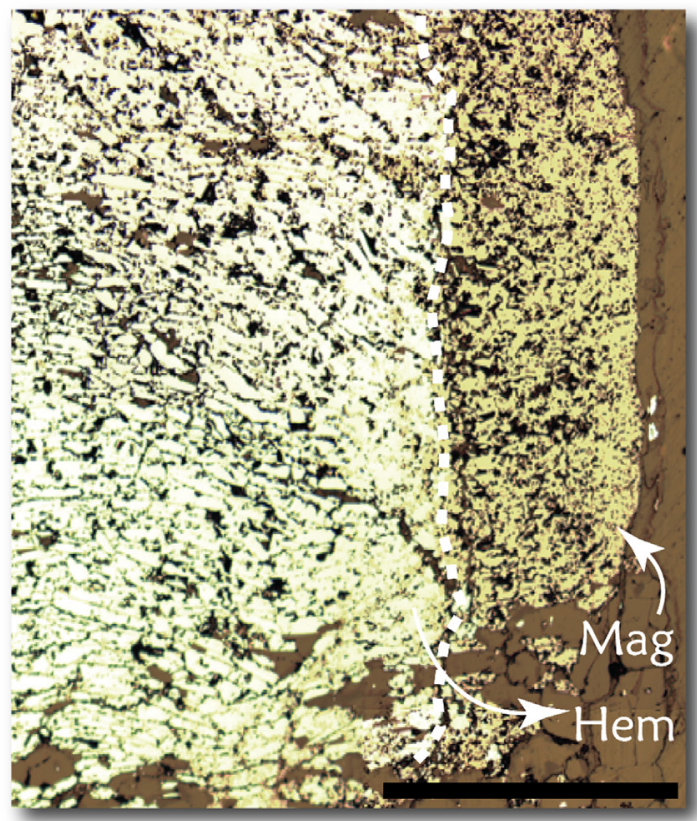

a) $900{ }^{\circ} \mathrm{C}, 1.5 \mathrm{GPa}, 10$ hours

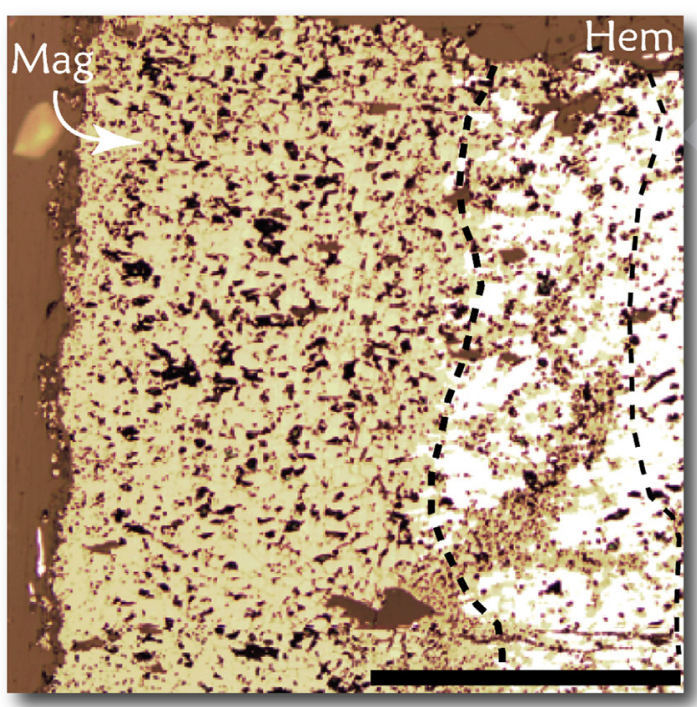

b) $900{ }^{\circ} \mathrm{C}, 1.5 \mathrm{GPa}, 75$ hours

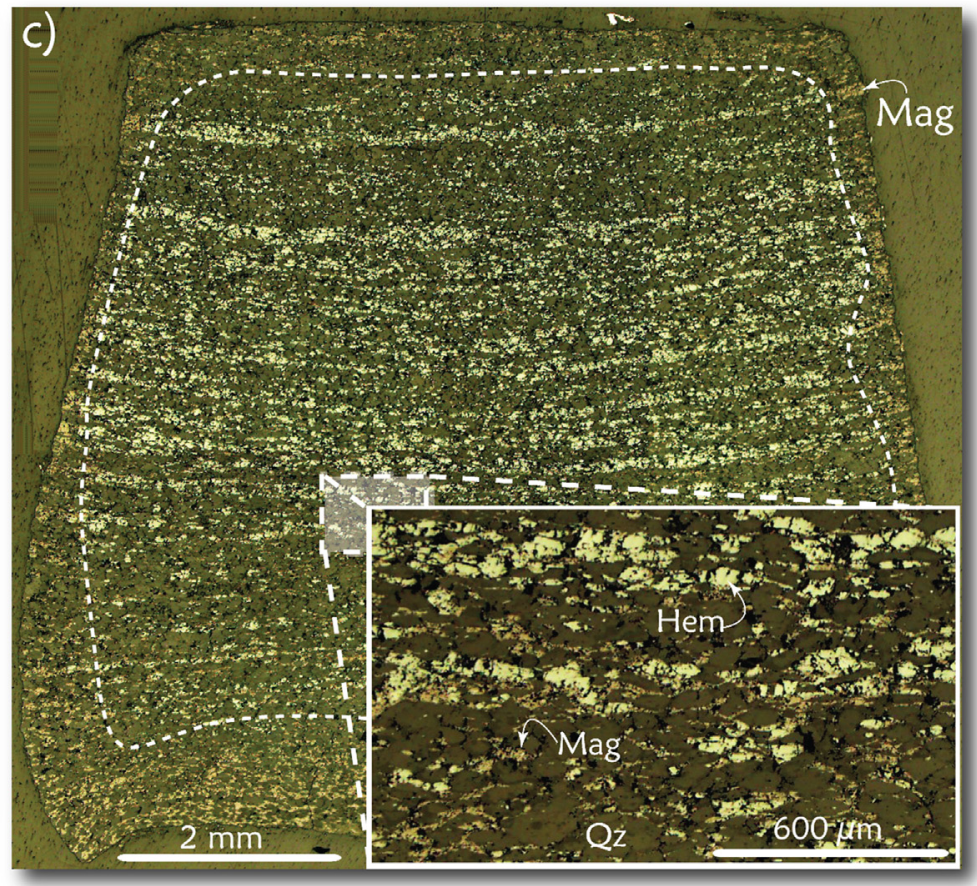

d)

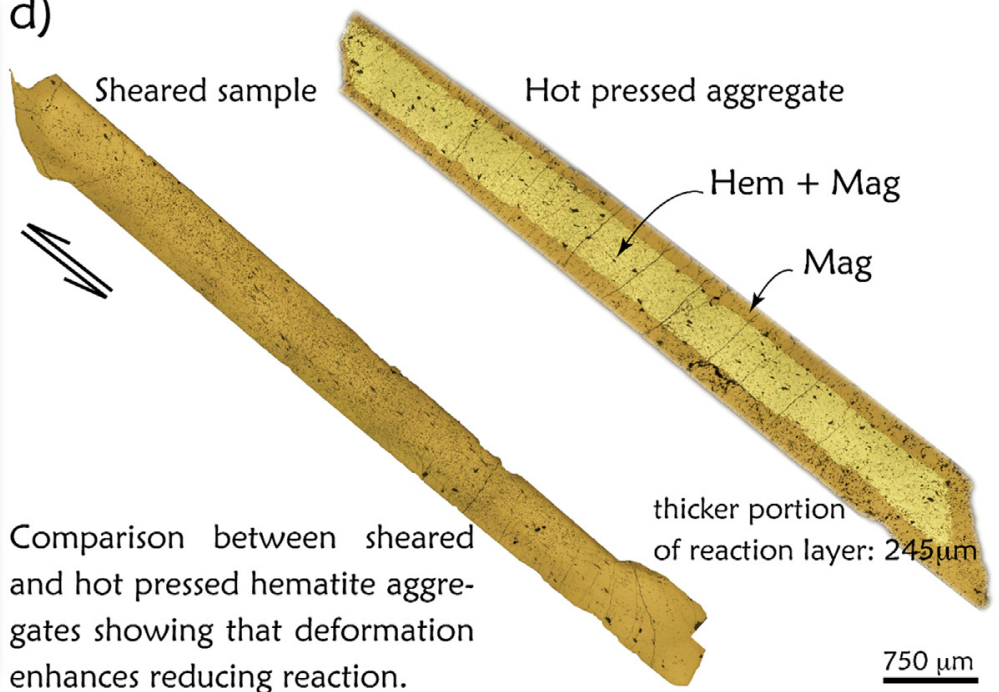

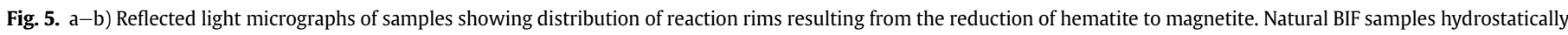

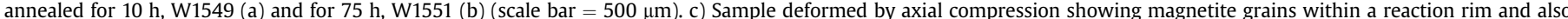

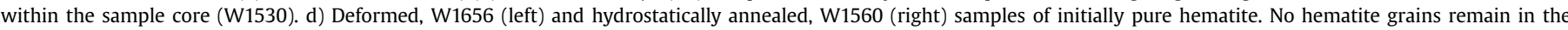

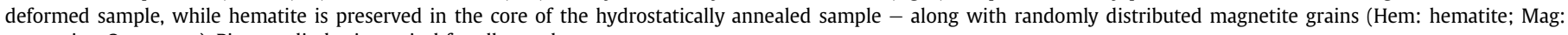
magnetite; Qz: quartz). Piston cylinder is vertical for all samples.

\subsection{Microstructures}

Optical and SEM micrographs are presented for both natural strong (SB) and weak banding (WB) aggregates deformed by axial compression, and synthetic and natural aggregates deformed by general shear. For general shear experiments, the samples were deformed to similar shear strains, thus differences in microstructure reflect differences in how deformation is accommodated. The synthetic quartz-iron oxide aggregates, which have an initially uniform distribution of hematite grains, are homogeneously deformed and developed typical mylonitic microstructures, regarding shear zone textures. In contrast, BIF bands deform heterogeneously, showing localized micro-shear zones related to variations in iron oxide content and distribution. The amount of quartz recrystallization is spatially associated with the distribution of very-fine grained reaction products surrounding iron oxide clusters (fayalite and/or ferrosilite depending on the presence of magnetite or hematite, respectively). Reaction products are composed of grains between 1 and $3 \mu \mathrm{m}$ (Fig. 6f). For this reason, fine grained fayalite and ferrosilite grains are not differentiated and are referred to as reaction products.

\subsubsection{Axial compression experiments}

3.3.1.1. Strong banding samples. Microstructures in quartz and hematite rich layers reveal heterogeneous deformation with strain localization into bands with higher oxide contents. Samples 

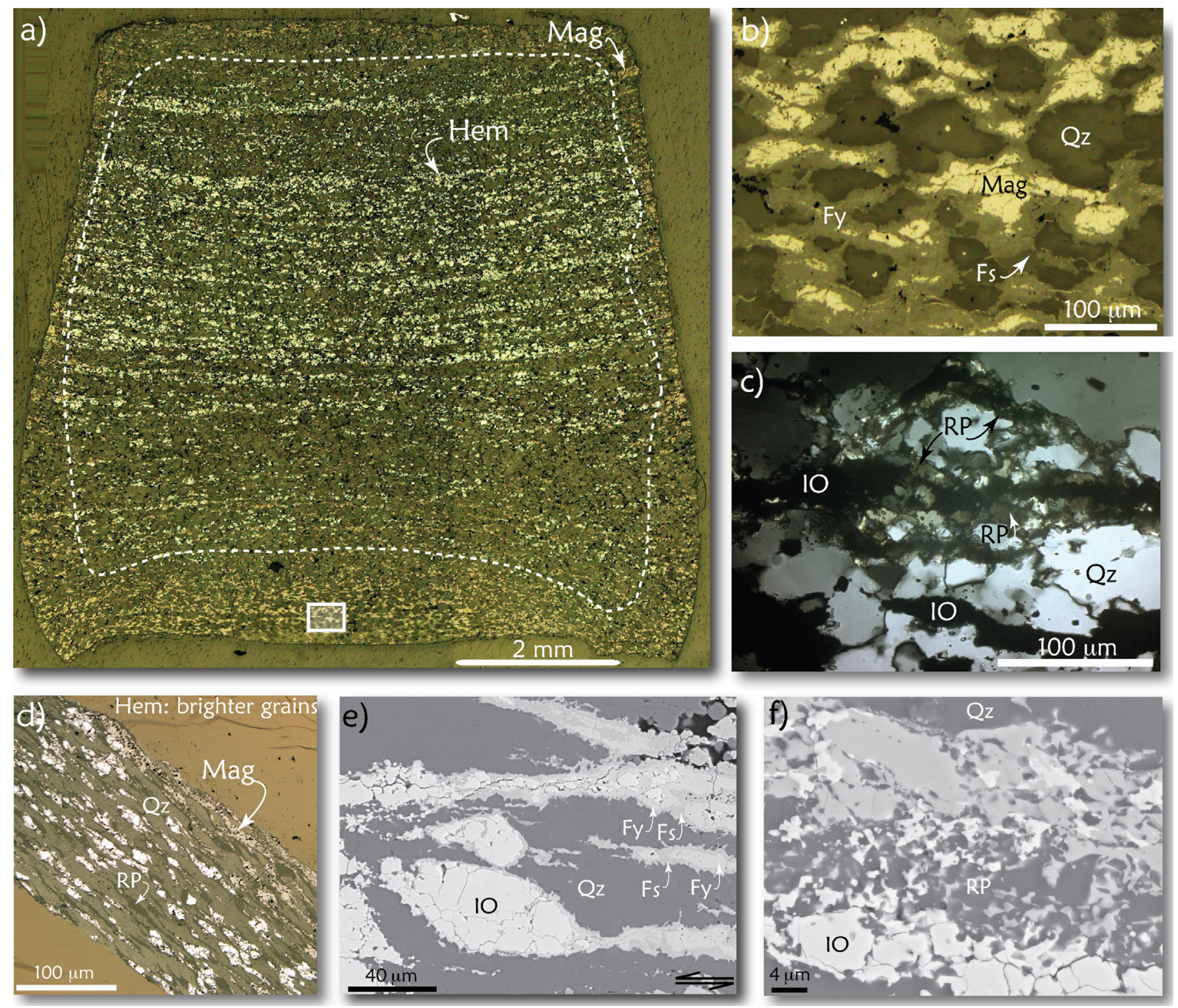

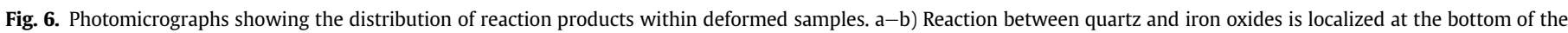
sample W1530 (WB sample) deformed in axial compression (reflected polarized light). Figure b shows higher magnification indicated by white square in 'a'. c) Reaction products forming thin isolated trails parallel to the foliation in sample (SB sample W1556) deformed in axial compression (crossed polarized light). d) Reaction products are widely dispersed within sheared slices of natural aggregates. Reaction products are surrounding clusters of iron oxide forming fine-grained trails (reflected polarized light). e) Detail of iron oxide surrounded by rim of fine-grained products resulting from the reaction of quartz and iron oxide to produce layers of ferrosilite and fayalite. f) Detail of a diffuse and fuzzy interface between quartz and iron oxide with a mixture of fine-grained reaction products and iron oxide (e-f, electron backscattered image, 20 KV; $d-f$ : sample W1608) (Hem: hematite; Mag: magnetite; IO: iron oxide; Qz: quartz; Fs: ferrosilite; Fy: fayalite; RP: reaction products, identified via microprobe).

deformed at $10^{-5} \mathrm{~s}^{-1}$ do not show recrystallized grains, and within quartz-rich layers (>90\% quartz) quartz grains appear nominally undeformed, or show slightly undulatory extinction and deformation lamellae (Fig. 7a). In these layers, quartz grain size is similar to that determined prior to deformation $(150 \mu \mathrm{m})$. In contrast, quartz grains surrounded by hematite flakes within hematite rich layers are clearly flattened (Fig. 7b). Hematite remains the dominant iron oxide phase, but magnetite grains are found throughout the hematite rich layers (Fig. 7c). On the edge of this sample, a reaction rim is seen, with a thickness up to $\sim 1 \mathrm{~mm}$, in which no hematite grains remain (Fig. 7c, W1533 - 10 h under experimental condition, $42 \%$ total axial strain).

At slower strain rate, $10^{-6} \mathrm{~s}^{-1}$, quartz shows undulatory extinction, deformation lamellae, modest subgrain formation and sutured grain boundaries with a few very-fine recrystallized grains (Fig. 7d). These features are more evident within iron oxide rich layers, while quartz grains in nominally pure quartz bands remain nominally free of intracrystalline deformation features. In the iron oxide rich layers, minor amounts of fine fayalite/ferrosilite grains $(<1 \%$, reaction products), form thin isolated trails parallel to the compositional banding/foliation (Fig. 6c). Magnetite locally becomes the main iron oxide phase (W1556, $83 \mathrm{~h}$ under experimental condition, $39 \%$ total axial strain).

3.3.1.2. Weak banding samples. For the weak banding samples deformed at $10^{-5} \mathrm{~s}^{-1}$, nominally pure quartz bands cannot be identified and most of quartz grains are surrounded by iron oxides (initially hematite grains). These oxides are distributed along 

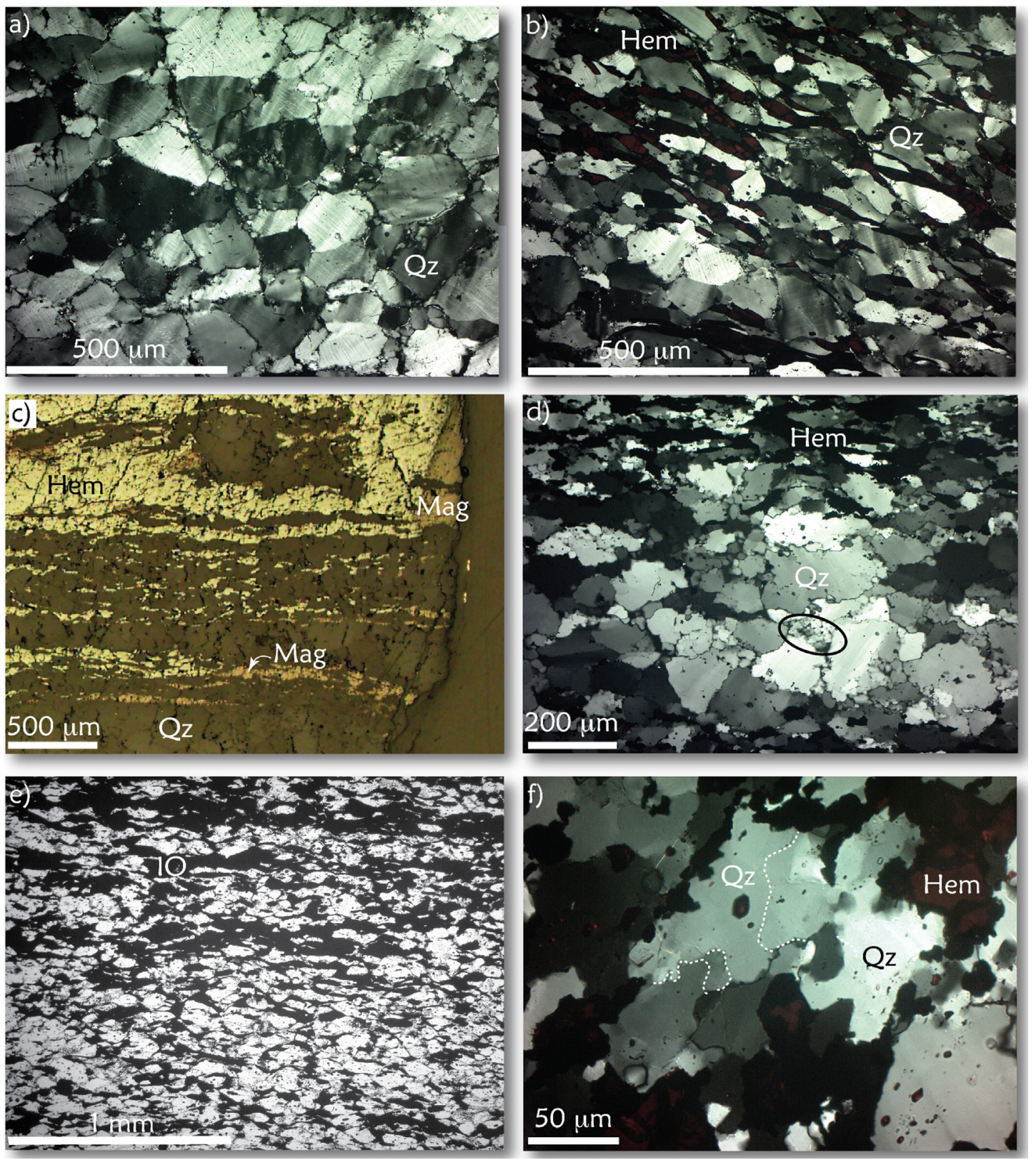

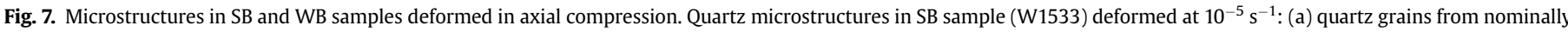

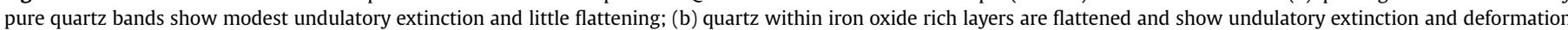

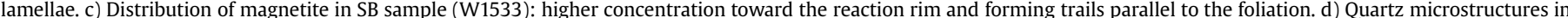

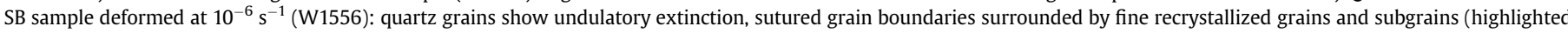

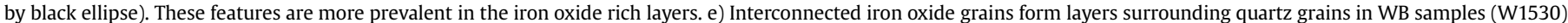

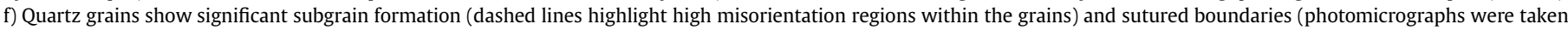
using crossed polarized light; exceptions: $c$ - reflected polarized light and $e$ - transmitted light) (Qz: quartz; Hem: hematite; Mag: magnetite; IO: iron oxide).

interconnected layers (Fig. 7e). Magnetite grains are randomly distributed throughout the samples, forming layers parallel to banding (when present) and obvious reaction rims at the edge of the sample (thickness: $200-450 \mu \mathrm{m}-$ Fig. $5 \mathrm{c}$ ). Deformation is homogeneous with no strain localization into specific layers. Most of the quartz grains show undulatory extinction and deformation lamellae, although undeformed quartz grains can be observed when they are not surrounded by iron oxides. At $10^{-6} \mathrm{~s}^{-1}$, quartz grains exhibit subgrains and features indicative of grain boundary migration at porphyroclast grain boundaries (Fig. 7f). Based on optical microscopy, iron oxides have very high aspect ratios with anastomosing shapes contouring around quartz grains (e.g., Fig. 7e).

\subsubsection{General shear experiments}

3.3.2.1. Synthetic aggregates. In the synthetic quartzite sample (W1592, final $\gamma=3.9$ ), a few isolated and elongated porphyroclasts (aspect ratio: 1:3) are observed in a matrix of very-fine recrystallized grains (Fig. 8a). These porphyroclasts show serrated boundaries, undulatory extinction and deformation lamellae, with no optical evidence of subgrain formation. These features suggest the process of bulging recrystallization, from Stipp et al. (2002) and 

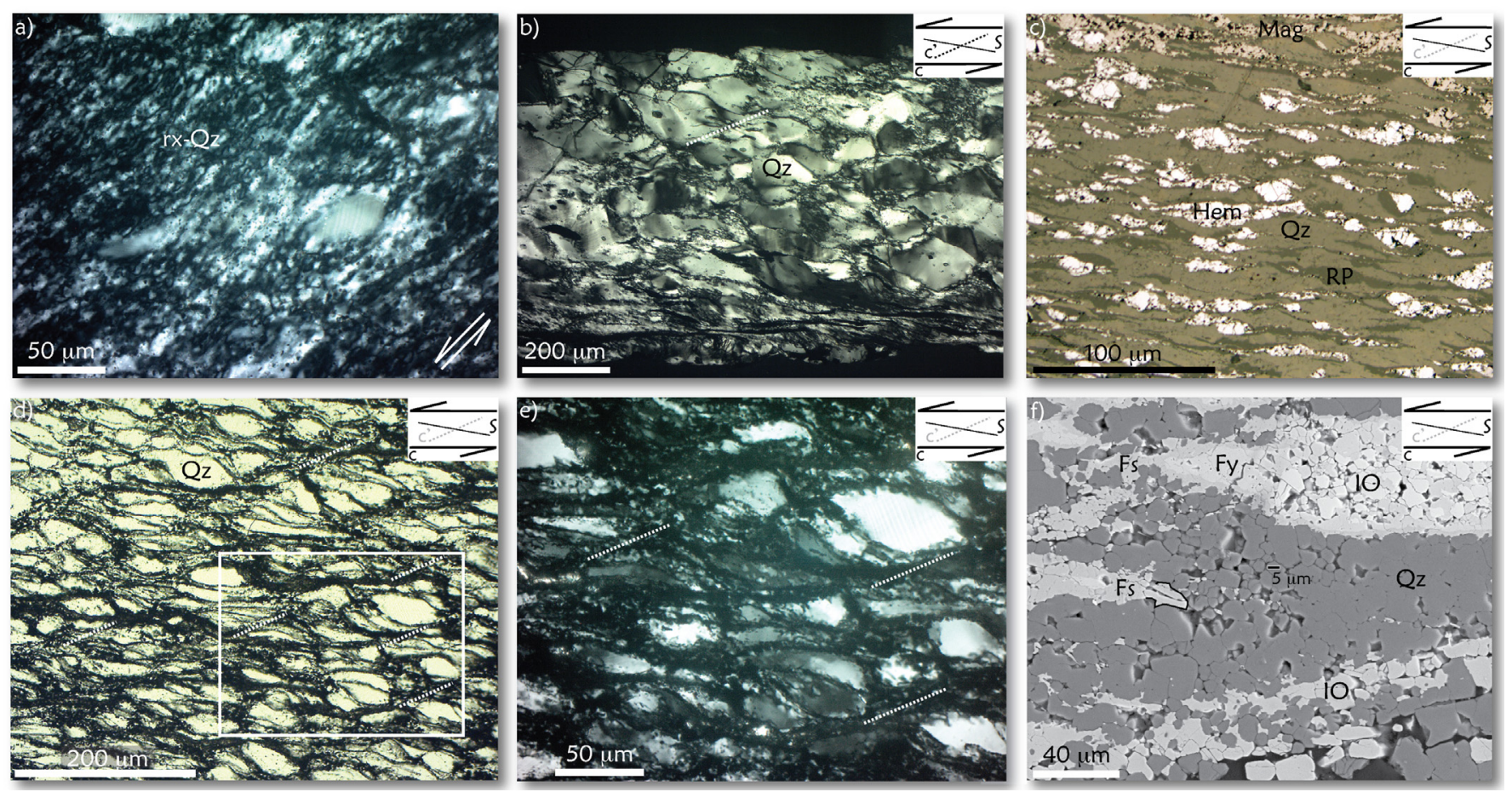

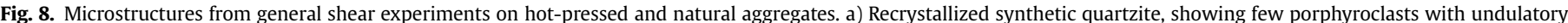

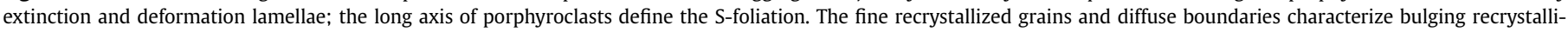

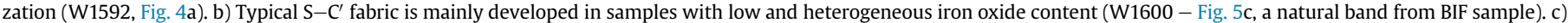

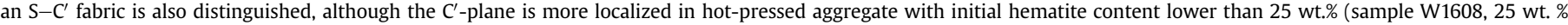

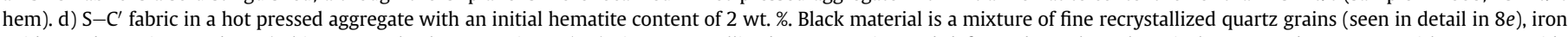

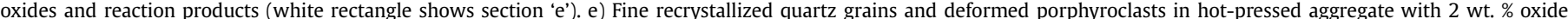

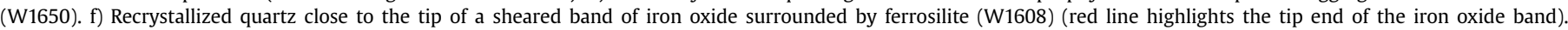

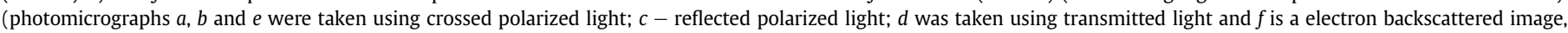

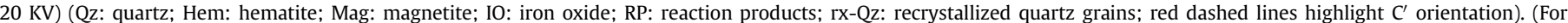
interpretation of the references to color in this figure legend, the reader is referred to the web version of this article.)

Stipp and Kunze (2008), treated as regime 1 dislocation creep by Hirth and Tullis (1992).

A pronounced $\mathrm{S}-\mathrm{C}$ fabric is a common feature to all sheared aggregates. In addition, the generation of $S-C^{\prime}$ fabrics is apparent in samples with iron oxides and reaction products (Fig. $8 \mathrm{~b}-\mathrm{e}$ ). In the pure quartz aggregate, the S-foliation is defined by the shape preferred orientation of porphyroclasts. In the oxide bearing samples, the iron oxides are distributed in layers parallel to the shear plane (C-foliation) and to the S-foliation. The thin iron oxide layers become interconnected in samples with initial hematite contents higher than $25 \mathrm{wt}$. \%, forming prominent networks surrounding clusters of quartz grains in samples with hematite contents of $\geq 50 \mathrm{wt}$. \%. In the sample with an initial hematite content of $25 \%$, the outline of quartz porphyroclasts can still be identified, but their cores show highly heterogeneous and undulatory extinction, deformation lamellae and subgrains; these features are similar to those observed in the WB sample deformed by axial compression at $10^{-6} \mathrm{~s}^{-1}$ (Fig. 7f). With increasing oxide content, recrystallized quartz grains (grain size up to $\sim 10 \mu \mathrm{m}$, based on optical and electron backscattered images) become more homogenously distributed throughout the samples.

All sheared samples with initial hematite contents $>25 \mathrm{wt}$. \% are more homogenously deformed and show preserved hematite grains; magnetite is more restricted to the edges of the samples (except the $100 \mathrm{wt}$. \% hematite aggregate). These samples show a well-developed S-foliation defined by elongate quartz porphyroclasts (mean value of aspect ratio: 3-4). Porphyroclast grain boundaries become more diffuse, owing to recrystallization and irregular intracrystalline deformation. With higher hematite contents, the $C^{\prime}$-planes become harder to distinguish, and are not resolvable for samples with initial oxide contents $\geq 50 \%$. These samples show isolated quartz porphyroclasts.

Samples with initial hematite contents $\leq 25$ wt.\% show iron oxide clusters surrounded by interconnected trails of reaction products; the reaction products form diffuse zones between quartz and iron oxide clusters (Fig. 6e-f). Even small amounts of hematite have significant effects on the microstructure. The sample with an initial hematite content of 2 wt. \% shows elongated quartz porphyroclasts (with average aspect ratio of 3 and grain sizes around $30 \mu \mathrm{m})$, sometimes surrounded by iron oxide grains, which together with reaction products define the S-foliation (Fig. 8d). Quartz grains show undulatory extinction, deformation lamellae and diffuse boundaries, due to the occurrence of fine recrystallized grains $(<10 \mu \mathrm{m})$ and reaction products (Fig. 8e). The $C^{\prime}$-plane is defined by recrystallized quartz grains and reaction product trails oriented at $\sim 20^{\circ}$ synthetic to the shear sense, defining narrow shear zones that connect iron oxide layers (Fig. 8d). Recrystallized quartz grains are spatially associated with reaction products (fayalite/ferrosilite) promoting the interconnection of iron oxide layers through $\mathrm{C}^{\prime}$-planes (Fig. 8d-f). The irregular distribution of recrystallized quartz grains and the development of $\mathrm{C}^{\prime}$-planes connecting iron oxide layers results in strain localization into narrow shear zones. Clusters of iron oxides and thin layers of reaction products (when present) define the $\mathrm{S}$-foliation.

In general, the $S$-foliation is oriented at $15-20^{\circ}$ from the shear plane (clockwise rotation), while C'-plane, when present, is 
oriented at $\sim 20^{\circ}$ synthetic to the shear sense (Fig. $8 \mathrm{~b}$ ). The shear plane (C-plane) is defined by iron oxide layers, which can be interconnected by reaction product trails ( $\mathrm{C}^{\prime}$-plane) (Fig. 8c-d). Pure iron oxide aggregates do not show obvious features of intracrystalline deformation or evidence of recrystallization under optical microscope.

3.3.2.2. Natural aggregates. Deformation microstructures are heterogeneous in the slices of BIF samples with low hematite content deformed in general shear. The samples with initial hematite contents lower than 10\% (W1587, W1600, W1676) show randomly distributed hematite grains (Fig. 9a). Quartz grains in the hematitepoor sample quenched at $\gamma=1.2$ (with $3 \%$ hematite, W1676) show strong undulatory extinction, deformation bands and deformation lamellae (Fig. 9b). Recrystallized quartz grains are not observed and there are no reaction products. Quartz grains are homogenously deformed. The slices sheared to higher strains (W1587, W1600) show strong strain localization. Recrystallized quartz is more abundant close to iron oxide grains (Figs. $8 \mathrm{f}$ and $9 \mathrm{c}-\mathrm{d}$ ); these recrystallized grains define a $\mathrm{C}^{\prime}$ plane oriented $20-25^{\circ}$ synthetic to the shear sense (Figs. 8b and 9c). Within the highly deformed regions, quartz grains are totally recrystallized, with very fine grains along the Sfoliation, oriented at $10-15^{\circ}$ from the shear plane (Fig. 9c).

Away from iron oxides, quartz porphyroclasts are preserved, although intensely deformed. Coarse quartz porphyroclasts are elongated parallel to the S-plane and show strong undulatory extinction, deformation lamellae, sutured and diffuse grain boundaries, sometimes surrounded by very fine recrystallized grains ( $<5 \mu \mathrm{m}$ in size) (Fig. 9c). Subgrains were not identified in optical and electron-backscattered images. This microstructural pattern is consistent with bulging recrystallization (Stipp et al., 2002; Stipp and Kunze, 2008) and regime 1 dislocation creep (Hirth and Tullis, 1992).

In the most deformed regions, iron oxides are progressively replaced by reaction products, which are initially concentrated along $\mathrm{C}^{\prime}$-planes, interconnecting iron oxide clusters. Within the highly sheared zones, the $\mathrm{C}^{\prime}$-plane is not recognized, and interconnected iron oxide/reaction product layers are oriented parallel to the C-plane (Fig. 9c-d).

While samples W1587 and W1600 share similar grain-scale microstructural features and hematite contents, a through-going shear zone is observed in sample W1600. This formation of the shear zone may explain the difference in strength of these samples (Fig. 3c). In the shear zone, recrystallized quartz grains bound a layer in which iron oxides are almost completely replaced by reaction products. The quartz porphyroclasts show undulatory extinction and deformation lamellae and are slightly elongated (Fig. 8b).

The microstructure of the BIF slice with 25\% hematite (W1625) is similar to that observed for the synthetic aggregate with an initial hematite content of 25 wt. \%. Sample W1625 exhibits a welldeveloped $\mathrm{S}-\mathrm{C}$ fabric and narrow $\mathrm{C}^{\prime}$-planes, defined by recrystallized quartz grains and reaction products (Fig. 8c). Clusters of iron
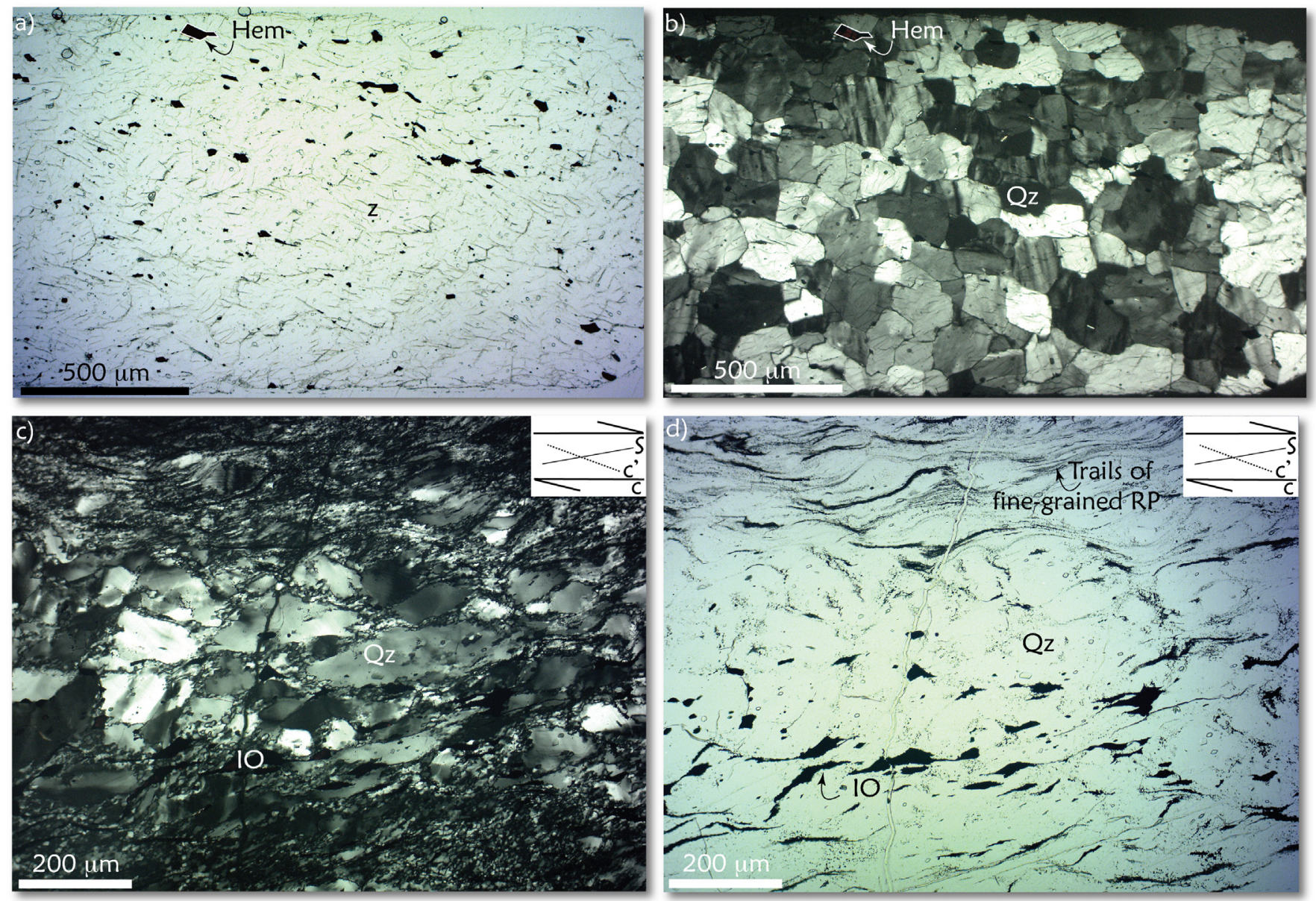

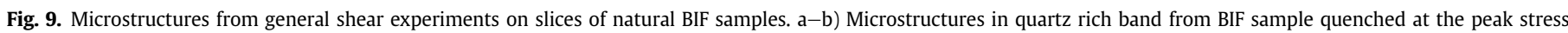

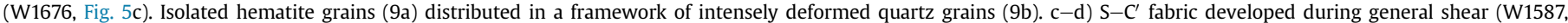

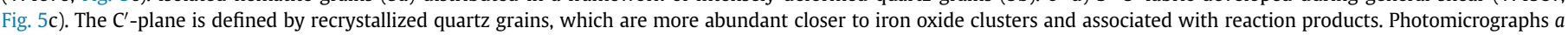
and $d$ were taken using transmitted light; $b$ and $c$ were taken using crossed polarized light; Qz: quartz; Hem: hematite; IO: iron oxide; RP: reaction products. 
oxide are interconnected by trails of reaction products, forming a network surrounding quartz porphyroclasts parallel to the S-foliation. Elongated quartz porphyroclasts (sometimes clusters of grains) also define the S-foliation, oriented at $\sim 20^{\circ}$ from the shear plane.

\section{Discussion}

Mechanical and microstructural data for BIF samples deformed in axial compression show the importance of the distribution of the weak phase and phase strength contrast (PSC) on the rheology of polyphase aggregates. In addition, data for the synthetic and natural (BIF bands) aggregates deformed in general shear illustrate the importance of PSC for flow stress, strain localization and fabric development, as well as how crystal-plastic deformation of quartz grains influences strain partitioning and strain localization.

The strength contrast between hematite and quartz has already been constrained from earlier studies conducted at conditions similar to our experiments. Chernak et al. (2009) conducted experiments on quartzite using the same techniques under the same conditions applied in our study, while Siemes et al. (2003) conducted experiments on hematite at the same temperature, but a confining pressure of $400 \mathrm{MPa}$. Our results, combined with these earlier studies show that quartz aggregates are considerably stronger than hematite aggregates - and suggest that there is little influence of confining pressure on the strength of hematite at these conditions. Samples with just $10 \%$ iron oxide are significantly weaker than $100 \%$ quartz samples, and strain weaken to steady state flow stress similar to that observed for a pure hematite aggregate (Fig. 3a-b, horizontal dashed line). These results demonstrate the importance of the volume proportion of the weak phase for the strength of polyphase aggregates (e.g. Handy, 1990, 1994; Tullis et al., 1991), although only modest effects are seen with oxide contents increasing above $10 \%$ (Figs. 3 and 4).

Strain weakening after $\sim 20 \%$ axial strain (Fig. 4a) and the microstructural characteristics (isolated porphyroclasts in a matrix of fine recrystallized grains) observed in the quartzite (sample W1592) have been reported in the literature (e.g. Stipp et al., 2002; Stipp and Kunze, 2008; Chernak et al., 2009) and interpreted to reflect recrystallization-accommodated dislocation creep, regime 1 of Hirth and Tullis (1992). In this case, the recrystallization process occurs by nucleation via a bulge mechanism, producing dislocation-free grains after grain boundary migration (e.g. Urai et al., 1986). Previous microstructural observations indicate that bulging recrystallization dominates during the onset of recrystallization at the peak stress. However, after strain weakening, evidence for both bulging recrystallization and subgrain development have been reported based on TEM and EBSD analyses (Hirth and Tullis, 1992; Stipp and Kunze, 2008).

A distinctive difference between the quartz-iron oxide samples deformed in general shear is that the natural aggregates exhibit pronounced strain weakening after the peak stress, whereas the synthetic samples do not. Microstructural observations suggest that this difference in mechanical behavior is caused by differences in the initial distribution of the iron oxides, microstructural evolution and dynamic recrystallization of quartz. Oxides are homogeneously distributed in the synthetic aggregates that exhibit nominally steady state flow. In contrast, the oxide distribution is more heterogeneous in the low oxide content samples that show pronounced strain weakening.

\subsection{The effect of compositional banding and fabric anisotropy on the strength}

Rosière et al. (2001), Siemes et al. (2003) and Morales et al. (2008) reported the relation between plastic deformation of BIF and the occurrence of specular hematite crystals. According to these authors, the syn-deformational growth of hematite platelets generates a pervasive foliation, enhancing the ductility. By analogy to the influence of mica reported for schists and gneisses, different degrees of the initial foliation in BIF samples may produce different strengths. This interpretation is generally supported by our observations on the strength of sheared BIF bands, although the results show that two different structures must be taken into account: the fabric anisotropy related to the foliation defined by the hematite platelets and the compositional banding, defined by differences in hematite content (i.e., weak banding versus strong banding samples). WB and SB samples with similar hematite content $(<10 \%)$ show different peak strength (Fig. $3 c$ - blue curves) and microstructural development. The fact that the synthetic aggregates with an initially isotropic distribution of iron oxides showed steady-state flow stress also illustrates the effect of the initial microstructure.

The strength of polyphase schists and gneisses is strongly controlled by initial anisotropy of the microstructure, which is in turn related to the abundance of the weak micas. Shea and Kronenberg (1993) and Tullis and Wenk (1994) showed that aggregates with interconnected mica (mica contents > 25\%) have lower strength than those in which mica is isolated in a quartzofeldspathic framework. Handy $(1990,1994)$ summarized this kind of mechanical behavior using two end-member microstructures. The first was treated as a framework-supported rheology (loadbearing framework - LBF), where the stronger phase controls the rheology and the weak phase remains isolated. The second was referred to as matrix-controlled rheology, where layers of interconnected weak phase (IWP) control the strength of the aggregate. In this view, the composite rheology is strongly dependent on the microstructure, although the volume proportion of the weak phase and the strength contrast among the phases is also important. Holyoke and Tullis (2006a) went further to show that strain becomes localized when mica is isolated, while strain remains more homogenous if mica is abundant and initially interconnected throughout the aggregate. The authors also argue that a foliation defined by dispersed mica grains (well-oriented for deformation) maximizes the PSC between strong and weak phase, enhancing strain localization.

The mechanical behavior of our weak (WB) and strong banding (SB) BIF samples (Fig. 3a-b) illustrates the effect of strain on the rheology of these samples. The WB samples, which exhibit interconnected layers of iron oxides surrounding quartz grains (a IWP texture), show flow stresses similar to that of pure hematite aggregates (Fig. 3a-b), characterizing a matrix-controlled rheology where the weaker phase controls the strength. In contrast, heterogeneous deformation of quartz grains and strength variation observed for SB samples suggests a transition from frameworksupported rheology to matrix-controlled rheology.

Within the iron-oxide rich layers of the SB samples deformed at $10^{-5} \mathrm{~s}^{-1}$, quartz grains are highly deformed even though the stronger quartz grains are surrounded by interconnected layers of the weak oxides. The strain weakening of these samples to a flow stress similar to that of pure hematite aggregates ( 270 MPa, Fig. $3 a-b$, strength of hematite pure aggregate from Siemes et al., 2003) suggests that load is initially borne by the stronger phase (quartz) and with progressive strain becomes accommodated by domains with IWP. The initial framework-supported rheology is then replaced by a matrix-controlled rheology, although the stronger phase is not passive and accommodates additional strain. At the slower strain rate of $10^{-6} \mathrm{~s}^{-1}$, the strength appears to be controlled by the weak phase, even though quartz grains are deformed. This behavior is similar to that described for synthetic quartz-muscovite aggregates deformed at $800{ }^{\circ} \mathrm{C}, 1.5 \mathrm{GPa}$, at two different strain rates (Tullis and Wenk, 1994). At the faster strain 
rate, strong strain partitioning into the muscovite layers was observed in samples with interconnected layers of muscovite surrounding quartz grains; quartz in these samples remained almost undeformed. In contrast, at slower strain rates the same type of sample showed homogenously deformed quartz grains. In this case, the aggregate maintains a matrix-controlled rheology, but the strong phase also accommodates strain. Holyoke and Tullis (2006a) correlated the occurrence of matrix-controlled rheology to the variation of the viscous strength contrast between the phases and strain rates. According to the authors, samples deformed at higher strain rates show higher strength contrast between the phases and developed highly localized shear zones, while samples deformed at slower strain rates showed the lowest strength contrast and deformed homogenously, with a typical matrix-controlled rheology.

The interpretation of the rheology of our samples is complicated by the progress of the reduction reaction, generating some magnetite in expense of hematite, as well as fine-grained reaction products (fayalite/ferrsosilite). The strengths of samples W1565 and W1530 are significantly different (Fig. 3a), even though they have similar iron oxide contents and similar banding. Sample W1565 was a strain rate stepping experiment (deformed at $10^{-5} \mathrm{~s}^{-1}$ after a long interval of deformation at $10^{-6} \mathrm{~s}^{-1}$ ), which allowed more time for reaction. Nevertheless, our data on pure magnetite samples indicate no resolvable strength difference between the two iron oxides (Fig. 4a).

\subsection{Phase strength contrast, weak phase interconnection and fabric development}

An intriguing aspect of the mechanical behavior of the BIF samples is the correlation of strain weakening with pervasive plastic deformation of quartz within iron oxide rich domains, compared to quartz in neighboring oxide-poor domains. Moreover, the reaction progress between quartz and iron oxides appears to be enhanced by deformation. Although minor amounts of isolated reaction products are identified in samples deformed by axial compression, these products are only observed within the highest strained domains. In sheared samples, reaction products are always recognized, commonly related to recrystallized quartz grains in highly strained regions. Syn-deformational reactions are recognized as an important cause of strain weakening and localization in experimental and naturally deformed aggregates (e.g. Stünitz and Tullis, 2001; Keller et al., 2004; de Ronde et al., 2004, 2005; Burlini and Bruhn, 2005; Holyoke and Tullis, 2006a,c). The quartz-iron oxide reactions in our samples provide new insights into generation and maintenance of high-strain zones.

The rheology of the synthetic quartz-iron oxide aggregates and BIF samples illustrate weakening related to the transition from load-bearing framework to interconnected weak phase fabric. The mechanical behavior is thus controlled by the (a) viscous strength contrast among quartz, iron oxides and reaction products; (b) the initial distribution and volume proportion of the weak phase (iron oxides $>10 \%$ ), if it is abundant enough to be interconnected prior to deformation (W1625); and (c) the microstructural evolution with progressive strain. If the weak phase is interconnected prior to deformation, it controls the rheology and there is no strain weakening and samples show steady state flow stress (Fig. 3c); in this case, an S-C fabric develops (Fig. 8c).

The distinctive quartz microstructures adjacent to iron oxides reflect grain-scale stress variation within the aggregates. Quartz microstructures indicative of regime 1 dislocation creep are observed in domains with interconnected layers of iron oxides. The sample with the highest peak stress (Fig. 3c - W1676) does not show reaction products at low strain, illustrating that the stress concentrations promoting recrystallization result from the strength contrast between quartz and iron oxides. With low hematite contents, the peak stresses of the BIF layers are similar to that of $100 \%$ quartz aggregates (Figs. $3 \mathrm{c}$ and $4 \mathrm{~b}$ ), indicating that the stress is initially borne by the quartz framework. In this case, the high local stress at the edges of iron oxide grains (weak phase) apparently leads to enhanced dynamic recrystallization, providing an explanation for the more strongly deformed quartz grains adjacent to iron oxides (Figs. $8 \mathrm{f}$ and $9 \mathrm{a}-\mathrm{d}$ ).

The degree of initial strain localization depends on the viscous strength contrast between the phases, and the subsequent extent of strain localization depends on the evolution of the PSC (Handy, 1994; Holyoke and Tullis, 2006a). The relative weakness of the recrystallized grains with respect to the porphyroclasts can promote high strain rates in the aggregates between the hardening porphyroclasts and surrounding recrystallized grains, providing a mechanism to enhance interconnection between the initially isolated weak phases.

The occurrence of reaction products associated with fine recrystallized quartz in our samples suggests a relation between dynamic recrystallization and syn-deformational reactions. The greater extent of reaction in the aggregates with initially dispersed iron oxide suggests that the reaction of hematite + quartz to magnetite + ferrosilite/fayalite was enhanced by grain size reduction of quartz, which in turn was initially promoted by dynamic recrystallization associated with the stress concentrations at oxidequartz boundaries. The formation of the fine-grained $(<2-3 \mu \mathrm{m})$ reaction products (ferrosilite/fayalite) results in diffuse quartz-iron oxides interphase boundaries and thin trails connecting clusters of iron oxide (Fig. 6d-f) in strongly strained domains. The finegrained products of the syn-deformational reactions, in addition to the deformed quartz grains, possibly deforming by grain boundary sliding (e.g. Halfpenny et al., 2006; Stipp and Kunze, 2008), can further promote diffusion-accommodated grain boundary sliding, strain localization and weakening (e.g. White and Knipe, 1978; Behrmann and Mainprice, 1987; Rubie, 1990; Brodie and Rutter, 1987; Newman et al., 1999; Keller et al., 2004; de Ronde et al., 2005; Holyoke and Tullis, 2006b). These interpretations are consistent with the observation that the quartziron oxide aggregates are weaker than the end-member aggregates at high strain (Figs. 3c and 4) and suggest that the reaction products deform by a grain-size sensitive creep process. The strength of a two-phase aggregate can be lower than that of its endmembers if grain-size pinning promotes grain size sensitive creep (e.g. Wheeler, 1992). Similar processes have been interpreted to produce the fabric evolution observed in a wide range of naturally deformed polyphase rocks (e.g., Fliervoet et al., 1997; Kruse and Stünitz, 1999; Killian et al., 2011; Speckbacher et al., 2013).

The suite of experiments on hot-pressed aggregates of quartz + hematite demonstrates that a small amount of hematite promotes pronounced weakening (Fig. 3c). The transition from a load-bearing framework to an interconnected weak phase texture can occur for weak phase contents as low as 2-10\% (Sample W1650, 2 wt. \% hematite; Figs. 3c and 8d). Fig. 4b illustrates the decrease in strength owing to increasing iron oxide content, and the insets show the effect of strain weakening. Our microstructural observations demonstrate the important role played by both quartz recrystallization and the generation of fine-grained reaction products. These processes allowed the interconnection of thin layers of the weak matrix that control the strength of the aggregate even with a high content of quartz porphyroclasts preserved at high strain $(\gamma=4.2)$ (Fig. 8d-e). The observation of nominally steady state flow stress at relatively low strain (W1650, Fig. 3c) indicates that under some conditions the IWP microstructure can be achieved rapidly. In contrast, the fabric of the BIF bands deformed in 

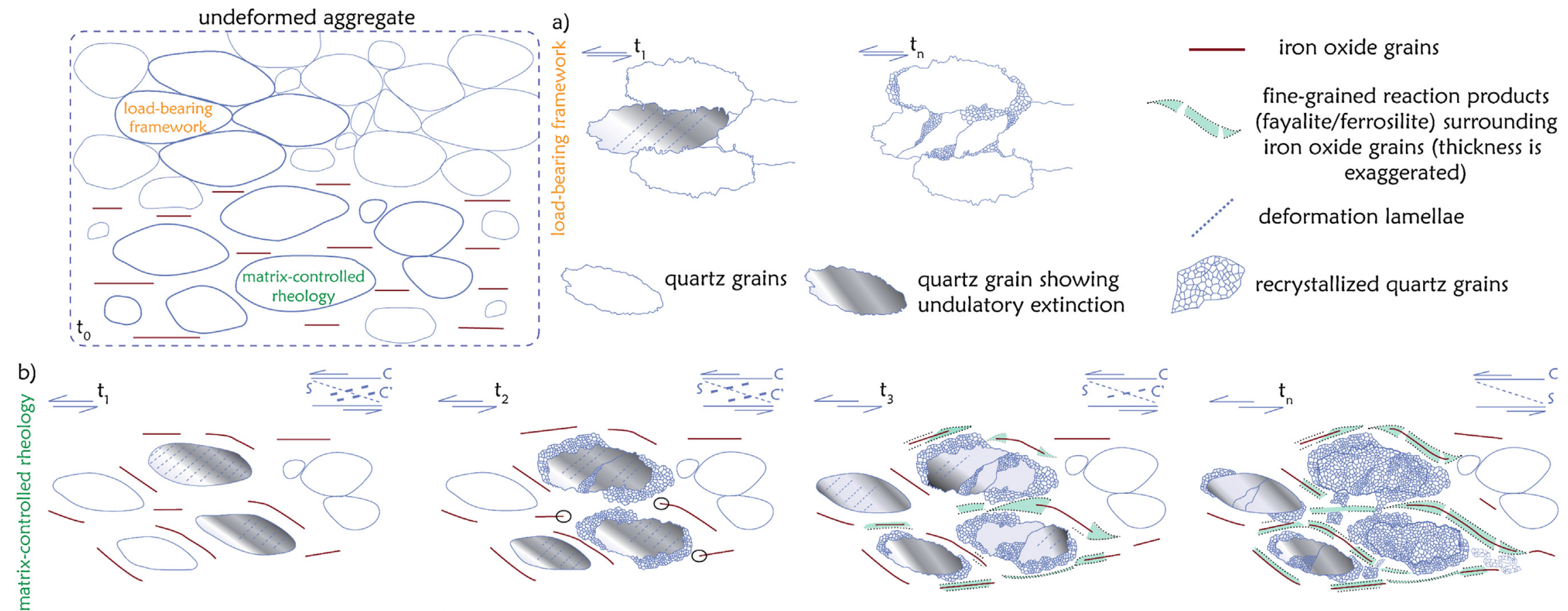

$t_{0}$

progressive strain

$t_{n}$

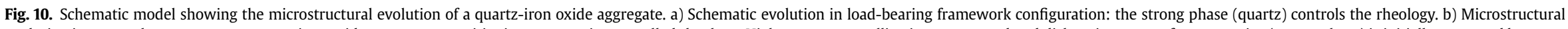
evolution in a two-phase aggregate quatz-iron (xide agregate transitioning to amaide a concentrations at the tips of ins products $\left(t_{3}\right)$, which presumably deform by grain size sensitive creep, allowing the interconnection of iron oxide layers and the transition from LBF to IWP microstructure ( $\left.t_{n}\right)$. 
general shear (Figs. 8b and 9) shows strain localization with the development of through-going weak bands, even though the load is initially born by the quartz framework (peak stress, Fig. 3, blue curves). The steady state flow stress is then rapidly attained due to drastic strain weakening (Fig. 3c); we propose that the lower stress results from shearing along localized regions of fine recrystallized quartz grains and fine-grained reaction products.

The transition from a load-bearing framework (Fig. 10a) to interconnected weak phase texture (Fig. 10b) and the generation of localized shear zones are associated with a progressive transition from $\mathrm{S}-\mathrm{C}^{\prime}$ to $\mathrm{S}-\mathrm{C}$ fabric (Fig. $10 \mathrm{a}-\mathrm{b}$ ). $\mathrm{S}-\mathrm{C}^{\prime}$ and $\mathrm{S}-\mathrm{C}$ fabrics are widely identified in naturally and experimentally deformed polyphase aggregates. While $S-C^{\prime}$ fabrics are associated with strain partitioning and localization, $\mathrm{S}-\mathrm{C}$ fabrics are a more typical feature of homogenously deformed aggregates (e.g. Berthe et al., 1979; Ramsay, 1980; Lister and Snoke, 1984; Lonka et al., 1998; Hippertt, 1999; Goodwin and Tikoff, 2002). For example, the Type II mylonites from Lister and Snoke (1984), who studied granitic and quartz-mica mylonites, show S-surfaces defined by elongated quartz grains and C-planes defined by mica trails in homogenously strained quartzites. Similarly, Goodwin and Tikoff (2002) showed that higher competency contrast (PSC) within the aggregates leads to strain localization into shear bands comprised of weak phase $\left(C^{\prime}\right)$, while if the phases present low competency contrast samples deform more homogenously developing S-C fabric.

Stünitz and Tullis (2001) sheared plagioclase aggregates with trace amount of water forming fine-grained zoisite, mica, quartz and kyanite. They observed that the strain was localized into the weak reaction products, deforming by diffusion-accommodated grain boundary sliding, on $C^{\prime}$ planes. Holyoke and Tullis (2006a) deformed fine-grained gneiss and showed that the development of $\mathrm{S}-\mathrm{C}$ and $\mathrm{S}-\mathrm{C}^{\prime}$ fabrics is linked to the strength contrast between the phases. High PSC leads to strain partitioning into the weaker phase, enhancing the development of $\mathrm{S}-\mathrm{C}^{\prime}$ fabric. In contrast, $\mathrm{S}-\mathrm{C}$ fabric develops at very low PSC, where strain is more homogenous. These lab data are consistent with observations from a wide variety of materials that indicate strain localization into shear bands $\left(C^{\prime}\right)$ is caused by high competency contrast between weak and strong phases (i.e., PSC) (Goodwin and Tikoff, 2002). Based on our mechanical and microstructural data, we associate the $\mathrm{S}-\mathrm{C}$, $\mathrm{S}-\mathrm{C}^{\prime}$ fabric to the transition from load-bearing framework to interconnected weak phase with decreasing phase strength contrast in the aggregate, in accordance with Holyoke and Tullis (2006a,c).

Our microstructures (Figs. 8 and 9) show that shearing between the weak matrix (recrystallized quartz and reaction products) and hardened porphyroclasts forms the $\mathrm{C}^{\prime}$ plane and allows the interconnection of iron oxides. Towards the high strain zones, the $\mathrm{C}^{\prime}$ plane becomes more discontinuous and within these micro shear zones (or in samples that deform homogenously) an $\mathrm{S}-\mathrm{C}$ fabric develops (Fig. 10b). The eventual formation of the $\mathrm{S}-\mathrm{C}$ fabric indicates a microstructurally-controlled evolution of the PSC between quartz and the iron oxides. In this case, the quartz microstructures also suggest a transition from dislocation creep regime 1 to regime 2 of Hirth and Tullis (1992), with the beginning of subgrain formation in more homogenously deformed samples that deform at low stress at high strain (Fig. 7f). We conclude that the transition from $\mathrm{S}-\mathrm{C}^{\prime}$ to $\mathrm{S}-\mathrm{C}$ fabric arises from a decrease in the PSC, which results from an evolution of the behavior of quartz after the formation of the IWP microstructure. The $S-C^{\prime}$ fabric suggests stress concentration and load initially borne by the strong phase (Fig. 10b $-t_{1}$ ). Stress concentration at the tip ends of iron oxide grains (platelets) leads to high stress recrystallization of quartz grains by bulging recrystallization (Fig. $10 \mathrm{~b}-t_{2}$ ). These grains react with iron oxides and generate fine-grained reaction products that further weaken the aggregate and promote strain localization (Fig. 10b $-t_{3}$ ). The development of $\mathrm{S}-\mathrm{C}$ fabric marks the breakdown of the LBF through the generation of IWP fabric, even though the strong phase in this case is not passive and also accommodates strain, progressively leading to a matrix-controlled rheology (Fig. 10b $-t_{n}$ ).

\section{Conclusions}

General shear experiments on pure quartz, hematite and magnetite aggregates showed that quartz is at least five times stronger than the iron oxides, while there is no resolvable strength difference between hematite and magnetite. Samples with different initial amounts of hematite, varied initial degree of mineralogical banding, and extents of reaction reveal some important implications for the rheology of Banded Iron Formation and deformation of polyphase rocks:

- The strength of Banded Iron Formation is dependent on iron oxide content, initial degree of mineralogical banding and strain.

- The rheology of samples with nominally pure quartz bands is supported by the load-bearing framework while in samples with weak banding it is controlled by the weak matrix.

- The strength contrast between quartz and iron oxides leads to stress concentration at the tips of isolated iron oxide grains and high stress recrystallization-accommodated dislocation creep of quartz grains. The recrystallized grains react with iron oxide producing fine-grained reaction products that may deform by grain size sensitive creep, enhancing strain localization, and promoting the interconnection of iron oxide clusters.

- Stress evolution and strain localization are associated with the development of $\mathrm{S}-\mathrm{C}^{\prime}$ fabric and the generation of high strain zones leading to drastic strain weakening. The generation of a pervasive interconnected weak phase leads to the subsequent development of an $\mathrm{S}-\mathrm{C}$ fabric.

\section{General conclusions include:}

- Sheared samples show that dynamic recrystallization of quartz grains and syn-deformational reactions have a profound effect on the strain-induced transition from load-bearing framework to interconnected weak phase mechanical behavior.

- Sheared samples demonstrate that the initial degree of mineralogical banding is an important factor for the generation of high strain zones. Samples with homogenous distribution of weak grains (synthetic aggregates) did not show strain localization and showed steady state flow stresses.

- The strain-induced transition from load-bearing framework to interconnected weak phase results in delocalization of deformation at high strain; $\mathrm{S}-\mathrm{C}^{\prime}$ fabric is related to initially high phase strength contrast within the aggregates, while $\mathrm{S}-\mathrm{C}$ fabric forms under condition of more homogeneous deformation.

\section{Acknowledgements}

We would like to thank Holger Stünitz and Jan Tullis for constructive discussions, Bill Collins for the thin section preparation, Issamu Endo for providing BIF samples and Jessica Till for sharing magnetite powder. Dr. Manuel Sintubin and Dr. Rudy Wenk are thanked for the careful editorial handling and Dr. Luiz F. G. Morales, Dr. Michael Stipp and an anonymous reviewer for constructive reviews. CCG is grateful to the Fundação de Amparo à Pesquisa do Estado de Minas Gerais (FAPEMIG - PROJECT APQ01210-14), Coordenação de Aperfeiçoamento de Pessoal de Nível 
Superior (CAPES) and Conselho Nacional de Desenvolvimento Científico e Tecnológico (CNPq) for the financial support; Jan Tullis for the motivation and assistance with sample assemblies; and those part of the "Brown's rock deformation gang" at the moment, especially: Terry Tullis, David Goldsby, Eric Goergen, Linda Chernak, Amanda Getsinger, Steve Kidder, Helen Doyle, for all sort of help and the excellent work environment during the time as visitor scholar at Brown University.

\section{References}

Behrmann, J.H., Mainprice, D., 1987. Deformation mechanisms in a hightemperature quartz-feldspar mylonite: evidence for super plastic flow in the lower continental crust. Tectonophysics 140, 297-305.

Berthe, D., Choukroune, P., Jegouzo, P. 1979. Orthogneiss, mylonite and non coaxial deformation of granites; the example of South Armorican shear zone. J. Struct. Geol. 1 (1), 31-42.

Bons, P.D., Cox, S.J.D., 1994. Analogue experiments and numerical modeling on the relation between microgeometry and flow properties of polyphase materials. Mater. Sci. Eng. A Struct. Mater. Prop. Microstruct. Process. 175 (1-2), 237-245.

Brodie, K., Rutter, E., 1987. The role of transiently fine-grained reaction products in syntectonic metamorphism: natural and experimental examples. Can. J. Earth Sci. 24, 556-564.

Burlini, L., Bruhn, D., 2005. High-strain zones: laboratory perspectives on strain softening during ductile deformation. Geol. Soc. Lond. Spec. Publ. 245, 1-24. http://dx.doi.org/10.1144/GSL.SP.2005.245.01.01.

Chernak, L.J., Hirth, G., Selverstone, J., Tullis, J., 2009. Effect of aqueous and carbonic fluids on the dislocation creep strength of quartz. J. Geophys. Res. 114, B04201. http://dx.doi.org/10.1029/2008JB005884.

de Ronde, A.A., Heilbronner, R., Stünitz, H., Tullis, J., 2004. Spatial correlation of deformation and mineral reaction in experimentally deformed plagioclase- olivine aggregates. Tectonophysics 389, 93-109.

de Ronde, A.A., Stünitz, H., Tullis, J., Heilbronner, R., 2005. Reaction-induced weakening of plagioclase-olivine composites. Tectonophysics 409, 85-106.

Dell'Angelo, L.N., Tullis, J., 1996. Textural and mechanical evolution with progressive strain in experimentally deformed aplite. Tectonophysics 256, 57-82.

Fliervoet, T.F., White, S.H., Drury, M.R., 1997. Evidence for dominant grain-boundary sliding deformation in greenschist- and amphibolite-grade polymineralic ultramylonites from the Redbank Deformed Zone, Central Australia. J. Struct. Geol. 19 (12), 1495-1520.

Gleason, G.C., Tullis, J., 1993. Improving flow laws and piezometers for quartz and feldspar aggregates. Geophys. Res. Lett. 20 (19), 2111-2114.

Gleason, G.C., Tullis, J., 1995. A flow law for dislocation creep of quartz aggregates determined with the molten salt cell. Tectonophysics 247, 1-23.

Goodwin, L.B., Tikoff, B., 2002. Competency contrast, kinematics, and the development of foliations and lineations in the crust. J. Struct. Geol. 24 (6-7), 1065-1085.

Halfpenny, A., Prior, D.J., Wheeler, J., 2006. Analysis of dynamic recrystallization and nucleation in a quartzite mylonite. Tectonophysics $427,3-14$.

Handy, M.R., 1990. The solid-state flow of polymineralic rocks. J. Geophys. Res. 95 (B6), 8647-8661.

Handy, M.R., 1994. Flow laws for rocks containing two non-linear viscous phases: a phenomenological approach. J. Struct. Geol. 16 (3), 287-301.

Heilbronner, R., Tullis, J., 2006. Evolution of c axis pole figures and grain size during dynamic recrystallization: results from experimentally sheared quartzite. J. Geophys. Res. 111, B10202. http://dx.doi.org/10.1029/2005JB004194.

Hippertt, J., 1999. Are S-C structures, duplexes and conjugate shear zones different manifestations of the same scale-invariant phenomenon? J. Struct. Geol. 21, 975-984.

Hirth, G., Tullis, J., 1991. The effect of porosity on the strength of quartz aggregates experimentally deformed in the dislocation creep regime. Tectonophysics 200 97-110.

Hirth, G., Tullis, J., 1992. Dislocation creep regimes in quartz aggregates. J. Struct. Geol. 14, 145-159.

Holyoke, C.W., Kronenberg, A.K., 2010. Accurate differential stress measurement using the molten salt cell and solid salt assemblies in the Griggs apparatus with applications to strength, piezometers and rheology. Tectonophysics 494, 17-31.

Holyoke, C.W., Tullis, J., 2006a. Mechanisms of weak phase interconnection and the effects of phase strength contrast on fabric development. J. Struct. Geol. 28, 621-640.

Holyoke, C.W., Tullis, J., 2006b. The interaction between reaction and deformation: an experimental study using a biotite + plagioclase + quartz gneiss. J. Metamorph. Geol. 24, 743-762.

Holyoke, C.W., Tullis, J., 2006c. Formation and maintenance of shear zones. Geology 34 (2), 105-108.

Jordan, P.G., 1987. The deformational behaviour of bimineralic limestone-halite aggregates. Tectonophysics 135, 185-197.

Keller, L.M., Abart, R., Stünitz, H., de Capitani, C., 2004. Deformation, mass transfe and mineral reactions in an eclogite facies shear zone in a polymetamorphic metapelite (Monte Rosa Nappe, Western Alps). J. Metamorph. Geol. 22 (2), 97-118.
Kilian, R., Heilbronner, R., Stünitz, H., 2011. Quartz grain size reduction in a granitoid rock and the transition from dislocation to diffusion creep. J. Struct. Geol. 33, 1265-1284.

Kronenberg, A.K., Tullis, J., 1984. Flow strengths of quartz aggregates: grain size and pressure effects due to hydrolytic weakening. J. Geophys. Res. 89, 4281-4297.

Kruse, R. Stünitz, H., 1999. Deformation mechanisms and phase distribution in mafic high-temperature mylonites from the Jotun Nappe, southern Norway. Tectonophysics 303, 223-249.

Lister, G.S., Snoke, A.W., 1984. S-C mylonites. J. Struct. Geol. 6 (6), 617-638.

Lonka, H., Schulmann, K., Venera, Z., 1998. Ductile deformation of tonalite in the Suomusjarvi shear zone, south-western Finland. J. Struct. Geol. 20 (6), 783-798.

Morales, L.F.G., Lagoeiro, L.E., Endo, I., 2008. Development of crystallographic fabric along folded polycrystalline hematite. J. Struct. Geol. 30, 1218-1228.

Muto, J., Hirth, G., Heilbronner, R., Tullis, J., 2011. Plastic anisotropy and fabric evolution in sheared and recrystallized quartz single crystals. J. Geophys. Res. 116, B02206. http://dx.doi.org/10.1029/2010JB007891.

Newman, J., Lamb, W., Drury, M., Vissers, R., 1999. Deformation processes in a peridotite shear zone: reaction-softening by an $\mathrm{H} 2 \mathrm{O}$-deficient, continuous net transfer reaction. Tectonophysics 303, 193-222.

Niemeijer, A.R., Spiers, C.J., 2005. Influence of phyllosilicates on fault strength in the brittle-ductile transition: insights from rock analogue experiments. In: Bruhn, D., Burlini, L. (Eds.), High-strain Zones: Structure and Physical Properties, vol. 245. Geological Society of London, London, pp. 303-327.

Olgaard, D.L., Ko, S.C., Wong, T.F., 1995. Deformation and pore pressure in dehydration gypsum under transiently drained conditions. Tectonophysics 245, 237-248.

Post, A., Tullis, J., 1998. The rate of water penetration in experimentally deformed quartzite: implications for hydrolytic weakening. Tectonophysics 295, 117-137. Ramsay, J.G., 1980. Shear zone geometry: a review. J. Struct. Geol. 2, 83-99.

Rawling, G., Baud, P., Wong, T., 2002. Dilatancy, brittle strength and anisotropy of foliated rocks: experimental deformation and micromechanical modeling. J. Geophys. Res. 107 (B10), 2234-2248.

Rosière, C.A., Siemes, H., Quade, H., Brokmeier, H.G., Jansen, E.M., 2001. Microstructure, texture and deformation mechanism in hematite. J. Struct. Geol. 23, $1429-1440$.

Rosière, C.A., Spier, C.A., Rios, F.J., Suckau, V.E., 2008. The Itabirites of the Quadrilatero Ferrifero and related high-grade iron ore deposits: an overview. Soc. Econ. Geol. (SEG) Rev, 15, 223-254.

Rubie, D.C., 1990. Mechanisms of reaction-enhanced deformability in minerals and rocks. In: Barber, D.J., Meredith, P.G. (Eds.), Deformation Processes in Minerals, Ceramics and Rocks. Unwin Hyman, London, pp. 262-295.

Rutter, E., Brodie, K., 1988. Experimental syntectonic dehydration of serpentinite under conditions of controlled pore water pressure. J. Geophys. Res. 93, 4907-4932.

Rutter, E., Brodie, K., 1995. Mechanistic interactions between deformation and metamorphism. Geol. J. 30, 227-240.

Schmidt, C., Bruhn, D., Wirth, R., 2003. Experimental evidence of transformation plasticity in silicates: minimum of creep strength in quartz. Earth Planet. Sci. Lett. 205, 273-280.

Shea, W.T., Kronenberg, A.K., 1992. Rheology and deformation mechanisms of an isotropic mica schist. J. Geophys. Res. 97 (11), 15201-15237.

Shea, W.T., Kronenberg, A.K., 1993. Strength and anisotropy of foliated rocks with varied mica contents. J. Struct. Geol. 9 (10), 1097-1121.

Siemes, H., Klingenberg, B., Rybacki, E., Naumann, M., Wolfgang, S.W., Jansen, E., Rosière, C.A., 2003. Texture, microstructure, and strength of hematite ores experimentally deformed in the temperature range $600-1100{ }^{\circ} \mathrm{C}$ and at strain rates between $10^{-4}$ and $10^{-6} \mathrm{~s}^{-1}$. J. Struct. Geol. 25, 1371-1391.

Siemes, H., Klingenberg, B., Rybacki, E., Naumann, M., Schafer, W., Jansen, E., Kunze, K., 2008. Glide systems of hematite single crystals in deformation experiments. Ore Geol. Rev. 33, 255-279.

Speckbacher, R., Stipp, M., Behrmann, J.H., Heidelbach, F., 2013. Fluid-assisted fracturing cataclasis, and resulting plastic flow in mylonites from the Moresby Seamount detachment, Woodlark Basin. J. Struct. Geol. 56, 156-171.

Stipp, M., Kunze, K., 2008. Dynamic recrystallization near the brittle-plastic transition in naturally and experimentally deformed quartz aggregates. Tectonophysics 448, 77-97.

Stipp, M., Stünitz, H., Heilbronner, R., Schmid, S.M., 2002. The eastern tonale fault zone: a 'natural laboratory' for crystal plastic deformation of quartz over a temperature range from 250 to 700 C. J. Struct. Geol. 24, 1861-1884.

Stipp, M., Tullis, J., Behrens, H., 2006. The effect of water, temperature and strain rate on the dislocation creep microstructure, recrystallized grain size and flow stress of quartz. Göttingen, TSK 11, 1-3.

Stünitz, H., Tullis, J., 2001. Weakening and strain localization produced by syndeformational reaction of plagioclase. Int. J. Earth Sci. 90, 136-148.

Terry, M.P., Heidelbach, F., 2006. Deformation-enhanced metamorphic reactions and the rheology of high-pressure shear zones, Western Gneiss Region, Norway. J. Metamorph. Geol. 24, 3-18.

Tullis, J., Tullis, T., 1986. Experimental rock deformation techniques. In: Hobbs, B.E., Heard, H.C. (Eds.), Mineral and Rock Deformation; Laboratory Studies: the Paterson Volume. American Geophysical Union, Washington, DC, pp. 297-324.

Tullis, J., Wenk, H.R., 1994. Effect of muscovite on the strength and lattice preferred orientation of experimentally deformed quartz aggregates. Mater. Sci. Eng. A175, 209-220.

Tullis, T.E., Horowitz, F.G., Tullis, J., 1991. Flow laws of polyphase aggregates from end member flow laws. J. Geophys. Res. 96, 8081-8096. 
Urai, J.L., Means, W.D., Lister, G.S., 1986. Dynamic recrystallization of minerals. In: Geophysical Monograph, vol. 36. American Geophysical Union, pp. 166-199.

Wheeler, J., 1992. Importance of pressure solution and Cable creep in the deformation of polymineralic rocks. J. Geophys. Res. 97, 4579-4589.
White, S.H., Knipe, R.J., 1978. Transformation- and reaction-enhanced ductility in rocks. J. Geol. Soc. 135, 513-516. http://dx.doi.org/10.1144/gsjgs.135.5.0513.

Yu, Y., Dunlop, D.J., Özdemir, Ö., 2002. Partial anhysteretic remanent magnetization in magnetite 1. Additivity. J. Geophys. Res. 107 (B10) http://dx.doi.org/10.1029/ 2001JB001249. 